\title{
Flame-Emission Spectrum of Water Vapor in the 1.9-Micron Region ${ }^{1,2}$
}

\author{
W. S. Benedict, ${ }^{3}$ Arnold M. Bass, and Earle K. Plyler
}

\begin{abstract}
The emission of hydrogen-oxygen and acetylene-oxygen flames has been studied by using a 15,000-lines-per-inch grating spectrometer with a lead-sulfide photoconductive detector. The water-vapor band, which in room-temperature absorption extends from about 1.80 to 1.96 microns, is broadened in emission to 1.7 to 2.2 microns. Nearly 1,000 lines have been measured, and a rotational analysis has been given for many of them. Many lines of the (011-000) band agree with those found in laboratory and atmospheric absoprtion, and many additional lines from higher energy levels may be identified. The principal series $J_{-J} \longleftrightarrow$ $(J+1)_{-(J+1)}$ may be followed out to $J=23$ in both $P$ and $R$ branches. Corresponding lines in the upper-state bands (021-010) and (031-020) have also been identified. A smaller number of lines may be assigned to the $(041-030),(051-040),(012-001), 022-011),(032-021)$, $(111-100)$, and $(121-110)$ bands.
\end{abstract}

\section{Introduction}

When hydrogen, hydrocarbons, or other hydrogencontaining compounds burn in air or oxygen, considerable energy is radiated in the infrared region. With spectrometers of low dispersion, three principal regions of strong emission were noted $[1]^{4}$ near 2.7 , 1.9 , and 1.4 microns. These correspond to regions of strong atmospheric absorption, due to water vapor $[2,3]$ and the emission must also be attributed to the $\mathrm{H}_{2} \mathrm{O}$ molecule. Studies of the emission with resolving power sufficient to separate lines due to individual rotational transitions in these rotationvibration bands have not previously been reported. Due to the great increase in resolving power in the near infrared region resulting from the use of photoconductive detectors, it is now possible to obtain spectra showing very much more detail, and to pursue the analysis to a point where the major part of the emission may be understood. In addition to the fundamental interest in determining the higher energy levels of the $\mathrm{H}_{2} \mathrm{O}$ molecule from spectra and in interpreting a rather complex spectrum, the present studies are also of practical importance in providing the data from which relative intensities within the $\mathrm{H}_{2} \mathrm{O}$ emission spectrum may be used to determine whether the $\mathrm{H}_{2} \mathrm{O}$ molecule appears in combustion processes in nonequilibrium distributions [4] and to determine the equilibrium "temperature" of that molecule in flames.

In this paper we present the results of measurements in the region 1.7 to $2.2 \mu\left(5,900\right.$ to $\left.4,600 \mathrm{~cm}^{-1}\right)$. When acetylene-oxygen and hydrogen-oxygen flames were observed with a 15,000-lines-per-inch grating spectrometer in this region, the intensity was sufficient so that slits subtending a spectral interval as narrow as $0.2 \mathrm{~cm}^{-1}$ could be used. This region (referred to for brevity as the $1.9-\mu$ region) is the most suitable for beginning the analysis of the vibration-rotation flame spectrum, for a number of

1 Supported in part by the Office of Naval Research.

2 Presented at the Symposium on Molecular Structure and Spectroscopy, Columbus, Ohio, June 1951.

3 Present address, The Johns Hopkins University, Baltimore, Md.

4 Figures in brackets indicate literature references at the end of this paper. reasons. The sensitivity of the lead-sulfide detector and the efficiency of the spectrometer are high; at the same time, the intensity of the emission is high without involving emissivities so great that selfabsorption effects cause distortion of the relative intensities. (There is some distortion of the intensities due to absorption of the lower-energy lines by the water-vapor molecules at room temperature in the spectrometer path, but this is confined to scattered frequencies in the center of the band, from 5,100 to $5,500 \mathrm{~cm}^{-1}[5]$.) The vibrational transitions involved in this region are few and do not show strong perturbations. The principal band, the only strong one in room-temperature absorption, is the transition $\left(v_{1}^{\prime} v_{2}^{\prime} v_{3}^{\prime}-r_{1}^{\prime \prime} v_{2}^{\prime \prime} v_{3}^{\prime \prime}\right)=(011-000)$. "Upper-state" bands, e. g., (021-010), (031-020), etc., also are excited at the high temperatures of the flame; these also involve states whose energies are well known from absorption studies and cause relatively little confusion. The "convergence" resulting from the difference in rotational constants between the upper and lower states of all these transitions is such that the bands are well spread out, with no regions where many lines crowd together.

Other regions in the emission spectrum of $\mathrm{H}_{2} \mathrm{O}$ have also been studied, but will not be reported in detail here. The $2.7-\mu$ region, in which the principal band is the $\nu_{2}$ fundamental, is extremely intense, with the result that both self-absorption and atmospheric absorption cause difficulties. Moreover, the 15,000 lines-per-inch grating with lead-sulfide detector loses sensitivity rapidly at wavelengths beyond $2.6 \mu$. Hence only the short-wavelength portion of this band ( $R$ branch) appears to advantage on our tracings. The 1.4- $\mu$ region is quite strong, so that resolution only slightly inferior to that achieved in the $1.9 \mu$ region was attained, but there are a number of vibrational transitions in the region, and convergence is such that the $R$ branches are extremely crowded (forming a characteristic head near 7,500 $\mathrm{cm}^{-1}$ ), while the $P$ branches fall in the region of strong $\mathrm{OH}$ emission [6]. At wavelengths shorter than $1.33 \mu$, the $\mathrm{H}_{2} \mathrm{O}$ emission becomes progressively weaker. The present observations extend to $1 \mu$, but 
slits as wide as $1 \mathrm{~cm}^{-1}$ were required to develop the bands centering around $1.1 \mu$, so that little detail in the rotational structure could be separated. In the photographic infrared and red [7] good resolution has been attained, especially in the region 7,100 to $8,800 \mathrm{~A}$; rotational analysis of this interval is in progress, but the structure is more complicated than in the $1.9-\mu$ region because the vibrational levels are more numerous and show perturbations. In addition to the emission measurements, studies have recently be made [8] of the absorption of heated $\mathrm{H}_{2} \mathrm{O}$ in the long-wavelength region greater than $4 \mu$. The observations in the spectral regions other than $1.9 \mu$ were useful in confirming many of the rotationvibration assignments made in the present paper.

\section{Experimental Procedure}

The spectrometer and the general arrangement for observing flame spectra have been described elsewhere [6]. In the present work, hydrogen-oxygen and acetylene-oxygen flames were observed, both just above the tip of the inner cone, and at greater heights in the outer cone. Various fuel-oxygen ratios in the neighborhood of stoichiometric were fed to the welding-torch burner. These varied conditions caused little change in the relative intensities of the emission in the $1.9-\mu$ region, a fact which indicates that practically all of the emission is due to the $\mathrm{H}_{2} \mathrm{O}$ molecule, and that the energy distribution for that molecule is not very sensitive to the burning conditions. This is to be expected, inasmuch as $\mathrm{H}_{2} \mathrm{O}$ is the major component of the burnt gas. Its emission, in regions other than those of active combustion (and with the type of burner used most of the radiation entering the spectrometer must come from such regions), would be predominantly thermal, characteristic of the weighted average temperature of the molecules in the line-of-sight of the spectrometer. With the fuel-oxygen ratios used, the maximum (adiabatic) temperatures attained did not vary greatly, and were in the neighborhood of $3,000^{\circ} \mathrm{K}$ for both hydrogen and acetylene as fuels. The hydrogen-oxygen emission was somewhat the stronger, the larger proportion of $\mathrm{H}_{2} \mathrm{O}$ in the burnt gas presumably overcoming the slightly higher temperatures in the acetylene-oxygen flame.

Four of the hydrogen-oxygen tracings, showing optimum resolution, were selected for the measurement of wavelength. Wavelength standards were obtained by superimposing on the emission spectra lines of either neon or krypton from gaseous discharges, focused through the flame. A smooth dispersion curve was fitted to the standard lines, and the $\mathrm{H}_{2} \mathrm{O}$ lines were measured with reference to this. Prominent lines were measured on all four tracings, and were usually concordant to $\pm 0.2 \mathrm{~cm}^{-1}$. Weaker lines were measured on one or two tracings, using the strong $\mathrm{H}_{2} \mathrm{O}$ lines in the neighborhood as secondary standards. In the center of the band, the strong absorption lines due to atmospheric water vapor could be used as checks on the emission measurements. Moreover, many weak lines that are ob- served in the absorption of large columns of water vapor [5, 9] appear strongly in emission in these tracings because of the much higher temperature in the flame. The measured positions of these lines are in good agreement with the absorption data. Because of the internal and external consistency of the measurements, it is believed that the frequencies of strong unblended lines are correct to within \pm 0.1 $\mathrm{cm}^{-1}$, and of the weaker or blended lines to \pm 0.25 $\mathrm{cm}^{-1}$. Wavelengths in air were converted to wave numbers and corrected to vacuum in the usual manner.

\section{Results}

A complete listing of the lines between 4,600 and $5,900 \mathrm{~cm}^{-1}$ has been prepared. Selected portions of this listing, corresponding to the regions of the $P, Q$, and $R$ branches as illustrated in figures 1 to 3 , are presented in table 1 . The first column gives the intensity, as observed on a typical $\mathrm{H}_{2}-\mathrm{O}_{2}$ tracing, in arbitrary units of recorder deflection above the background of unresolved emission in the neighborhood. The intensities are uncorrected for instrumental sensitivity and hence can be given only rough quantitative significance; the sensitivity, however, does not vary greatly over the frequency interval studied. Lines whose intensity and position are very strongly affected by atmospheric absorption are marked with an asterisk (*). It should be mentioned that the peak deflection of the most intense lines is of the order of one-tenth of that for a black body at the flame temperature. Making allowance for the fact that the slit width exceeds the line width, it is estimated that the maximum emissivity at the center of strong lines does not exceed 0.2 to 0.4 . This would appear to be experimentally confirmed by the fact that the peak deflection was very nearly doubled when a mirror reflected the flame upon itself, thus doubling the effective path of hot gas in the line of sight of the spectrometer. The second column of the table gives the position, in $\mathrm{cm}^{-1}$. The remaining columns of the table list rotational assignments for the observed absorption.

The measured region contains over 1,000 lines. These include all lines with a measured intensity of 10 or greater (the strongest observed line, 4,999.99 $\mathrm{cm}^{-1}$, having an intensity of 90 ), together with some weaker lines down to $I=3$ at the wings of the band. The noise level of the instrument and flame instability corresponded to $I\langle 2$, so that all lines, which have been observed on several tracings, are considered definite peaks in the emission. Many weaker lines of probable but not certain reality might have been added, and there is also a background of unresolved emission, whose intensity, in the stronger portions of the band, may reach 5 to 10 units. Some of the strongest atmospheric-absorption lines, arising from the lowest energy levels of the ground state, appear as dips in this background. There is little question but that if still higher resolving power could be used, many more "lines" would appear in this region. However, as will be discussed presently, 
TABLE 1. Emission lines in the region $1.9 \mu$ due to $\mathrm{H}_{2} \mathrm{O}$

\begin{tabular}{|c|c|c|c|c|c|c|c|c|c|}
\hline \multicolumn{2}{|c|}{ Observed } & Identification & \multicolumn{2}{|c|}{ Caìcuilated } & \multicolumn{2}{|c|}{ Observed } & \multirow{2}{*}{$\begin{array}{l}\text { Identification } \\
J^{\prime} \tau-J^{\prime \prime} \tau\end{array}$} & \multicolumn{2}{|c|}{ Calculated } \\
\hline $\begin{array}{l}\text { Inten- } \\
\text { sity }\end{array}$ & $\begin{array}{c}\text { Wave } \\
\text { number } \\
\nu_{\text {vac }}\end{array}$ & $J^{\prime} \tau-J^{\prime \prime} \tau$ & $\begin{array}{c}\text { Wave } \\
\text { number } \\
\nu_{\text {vac }}\end{array}$ & $\begin{array}{l}\text { Intensity } \\
\left(\sim 2,877^{\circ} \mathrm{K}\right)\end{array}$ & $\begin{array}{l}\text { Inten- } \\
\text { sity }\end{array}$ & $\begin{array}{c}\text { Wave } \\
\text { number } \\
\nu_{\text {vac }}\end{array}$ & & $\begin{array}{c}\text { Wave } \\
\text { number } \\
\nu_{\mathrm{vac}}\end{array}$ & $\begin{array}{l}\text { Intensity } \\
\left(\sim 2,877^{\circ} \mathrm{K}\right)\end{array}$ \\
\hline & $\begin{array}{c}\mathrm{cm}^{-1} \\
4910.80\end{array}$ & b $16_{-14-13}-17_{-15-14}$ & $c m^{-1}$ & & & 6383 & & $\mathrm{~cm}^{-1}$ & \\
\hline 50 & & $\mathrm{~g} \quad 8_{-8}^{-13}-9_{-9}^{-15},-14$ & 4910.6 & $\begin{array}{r}13 \\
3\end{array}$ & $\begin{array}{l}30 \\
37\end{array}$ & $\begin{array}{l}63.83 \\
65.39\end{array}$ & $\begin{array}{l}\text { f } \\
\text { a } 16_{-12,-11}-17_{-13,-12}\end{array}$ & $\begin{array}{l}63.69 \\
65.4\end{array}$ & $\begin{array}{r}3 \\
13\end{array}$ \\
\hline 45 & 12. 07 & a $18_{-16},-15-19_{-17},-16$ & 12.0 & 12 & & & d $\quad 9_{-9},-8-10_{-10},-9$ & & 10 \\
\hline 20 & 13. 07 & & & & 37 & 65. 74 & a $\quad 14_{-4}-15_{-5}$ & 65. 8 & 9 \\
\hline 25 & 14. 62 & j $12-12,-11-13_{-13},-12$ & 14. 22 & 6 & & & $\mathrm{~g} \quad 5_{0}-6_{1}$ & 65. 8 & 2 \\
\hline 22 & 15. 83 & j $\quad 12_{-10},-9-13_{-11},-10$ & 15. 8 & 5 & 18 & 66.60 & e $12_{-12},-11-13_{-13},-12$ & 66.8 & 6 \\
\hline $\begin{array}{l}16 \\
18\end{array}$ & $\begin{array}{l}\text { 16. } 49 \\
\text { 17. } 13\end{array}$ & h $\quad 9-9,-8-10_{-10,-9}$ & $---1--$ & 6 & $\begin{array}{l}25 \\
14\end{array}$ & $\begin{array}{l}67.00 \\
68.37\end{array}$ & & $\begin{array}{l}66.9 \\
68.5\end{array}$ & $\begin{array}{l}9 \\
5\end{array}$ \\
\hline $\begin{array}{l}18 \\
18\end{array}$ & 17. 87 & & & & $\begin{array}{l}1 \pm \\
35\end{array}$ & 68. 98 & e $12-10,-9-13-11,-10$ & 00.5 & 5 \\
\hline 15 & 18. 74 & e $14_{-14,-13}-15_{-15},-14$ & 18.8 & 6 & 35 & 69.15 & a $\quad 16_{-10}-17_{-11}$ & 69.2 & 9 \\
\hline 20 & 19. 28 & & & & 35 & 69. 46 & & & \\
\hline 20 & 20. 25 & $g \quad 6_{-2}-7_{-3}$ & 19. 98 & 1 & 17 & 70.53 & $5_{-4}-6_{-5}$ & 70.37 & 2 \\
\hline 14 & 21. 31 & f $\quad 10_{-10,-9}-11_{-11},-10$ & 20.3 & 4 & $\begin{array}{l}30 \\
60\end{array}$ & $\begin{array}{l}\text { 71. } 47 \\
73.16\end{array}$ & $\begin{array}{l}\text { b } \quad 12_{-6}-13_{-7} \\
\text { c } 11_{-11,-10}-12_{-12,-11}\end{array}$ & 71.4 & $\begin{array}{l}11 \\
15\end{array}$ \\
\hline 10 & 22. 14 & & & & & & $\mathrm{f} \quad 6_{0}-7_{-1}$ & 73. 07 & 2 \\
\hline 45 & 23. 17 & & & & & & $4_{-2}-5_{-3}$ & 73. 46 & 2 \\
\hline 50 & 24. 05 & d $11_{-11,-10}-12_{-12},-11$ & & 10 & 45 & 74. 40 & $14_{-6}-15_{-7}$ & & 9 \\
\hline & & a $18-14,-13-19-15,-14$ & 24. 2 & 10 & & & $\mathrm{~b}-13_{-8}-14_{-9}$ & 74. 4 & 11 \\
\hline 40 & & & 24. 7 & 16 & 50 & 75. 66 & a $15_{-15,-14}-16_{-16,-15}$ & 75. 6 & 19 \\
\hline 19 & & $\mathrm{k} \quad 9_{-9,-8}-10_{-10,-3}$ & 25. 35 & 4 & 55 & 76. 72 & b $13_{-13},-12-14_{-14},-13$ & 76.7 & 20 \\
\hline 17 & $\begin{array}{l}25.72 \\
26.51\end{array}$ & & & & 50 & 78. 46 & b $13_{-11,-10}-14_{-12,-11}$ & 78. 4 & 17 \\
\hline $\begin{array}{l}12 \\
56\end{array}$ & & & & & 14 & 80. 12 & $\mathrm{j} \quad 9_{-9,-8}-10_{-10,-9}$ & 80.13 & 6 \\
\hline $\begin{array}{l}56 \\
50\end{array}$ & 27. 99 & Б $15-15,-14-16-16,-15$ & 27.7 & 17 & $\begin{array}{l}19 \\
30\end{array}$ & $\begin{array}{l}80.98 \\
81.70\end{array}$ & & & \\
\hline 50 & 28. 11 & c $13_{-13},-12-14_{-14},-13$ & & 14 & 30 & 82.07 & a $15_{-13,-12}-16_{-14,-13}$ & 82.5 & 16 \\
\hline 20 & 28. 92 & & & & 25 & 82.90 & & & 10 \\
\hline 20 & 29. 17 & & & & 28 & 83. 48 & a $\quad 14_{-2}-15_{-3}$ & 83. 3 & 9 \\
\hline 15 & 30.55 & & & & 40 & 84.05 & a $15_{-11,-10}-16_{-12,-11}$ & 84. 1 & 13 \\
\hline 40 & 31. 16 & g $\quad 7_{-7,-6}-8_{-8,-7}$ & 31. 20 & 3 & 25 & 85. 36 & d $\quad 8_{-8}-9_{-9}$ & 85. 36 & 7 \\
\hline 36 & 33. 29 & b $15_{-13,-12}-16_{-14,-13}$ & $\ldots \ldots$ & 14 & & & $15_{-8}-16_{-9}$ & 85.5 & 9 \\
\hline 34 & 33. 48 & & & & 16 & 86. 14 & & & \\
\hline 26 & 33. 94 & b $15_{-11},-10-16_{-12},-11$ & 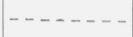 & 12 & 16 & 86.50 & $8_{-7}-9_{-8}$ & 86.57 & 2 \\
\hline 17 & 34. 82 & a. $17-15-14-18-16-15$ & & & 15 & $\begin{array}{l}\text { 87. } 34 \\
88.22\end{array}$ & & & \\
\hline 48 & 35.67 & $\begin{array}{lc}\text { a } & 17-15,-14-18_{-16},-15 \\
\text { g } & 6-4-7-5\end{array}$ & $\begin{array}{l}35.6 \\
35.67\end{array}$ & $\begin{array}{r}13 \\
2\end{array}$ & $\begin{array}{l}16 \\
35\end{array}$ & $\begin{array}{l}\text { 88. } 22 \\
89.18\end{array}$ & e $\quad 11_{-9,-8}-12_{-10,-9}$ & 89.2 & 6 \\
\hline 28 & 36. 28 & 12 & & & 25 & 90.00 & e $11_{-11,-10}-12_{-12},-11$ & 89. 98 & 7 \\
\hline 30 & 26. 65 & j $11_{-11},-10-12_{-12},-11$ & 36.62 & 6 & & & g $\quad 4_{-4}-5_{-5}$ & 90.10 & 2 \\
\hline 30 & 37. 27 & & & & 35 & 91.58 & $12_{-8}-13_{-9}$ & 91.5 & 11 \\
\hline 20 & 38. 29 & & & & 10 & 92.72 & $6_{-4}-7_{-5}$ & 93.08 & 2 \\
\hline 30 & 39. 70 & & & & 35 & 94.06 & & & \\
\hline 25 & 42. 49 & f $\quad 9_{-9,-8}-10_{-10,-9}$ & 42. 20 & 4 & 35 & 95. 23 & & & \\
\hline $\begin{array}{l}30 \\
30\end{array}$ & $\begin{array}{l}43.42 \\
43.75\end{array}$ & 13 & 43,75 & & 16 & 96.04 & c $\quad 10_{-10},-9-11_{-11},-10$ & 95.81 & 15 \\
\hline $\begin{array}{l}30 \\
35\end{array}$ & $\begin{array}{l}43.75 \\
44.76\end{array}$ & $\begin{array}{l}\text { e } 13-13,-12-14_{-14},-13 \\
\text { a } 17_{-13,-12}-18_{-14},-13\end{array}$ & $\begin{array}{l}43.75 \\
44.7\end{array}$ & $\begin{array}{r}6 \\
11\end{array}$ & 20 & 96.67 & f $\quad 6_{2}-7_{1}$ & & \\
\hline & & d $10_{-10,-9}-11_{-11},-10$ & & 10 & 25 & 97. 44 & $14_{-8}-15_{-9}$ & 97. 67 & 9 \\
\hline 20 & 45. 71 & $\mathrm{k} \quad 8_{-7}-9_{-8}$ & 45.7 & 3 & 17 & 98.54 & $15_{0}-16_{-1}$ & & 5 \\
\hline 14 & 46. 56 & e $13_{-11,-10}-14_{-12},-11$ & 46. 8 & 5 & 90 & 99.99 & $\mathrm{~b} \quad 12_{-10}-13_{-11}$ & 99. 79 & 14 \\
\hline 12 & 47. 02 & & & & & & b $12_{-12},-11-13_{-13},-12$ & 99. 94 & 21 \\
\hline 20 & 48. 66 & & & & & & a $14_{-14},-13-15_{-15},-14$ & 5000.10 & 21 \\
\hline 35 & 49. 08 & & & & 26 & 5001.07 & a $\quad 14_{-7}-15_{-8}$ & 5000. 92 & 3 \\
\hline 35 & 49. 27 & & & & & & $8_{-4}-9_{-5}$ & 01.04 & 9 \\
\hline 45 & 50.46 & a $16_{-16},-15-17_{-17},-16$ & 50.4 & 18 & 17 & 01.55 & $8_{-7}-9_{-8}$ & & 5 \\
\hline 55 & 51. 28 & c $12_{-12},-11-13_{-13,-12}$ & & 14 & 12 & 02. 91 & d $\quad 6_{-4}-7_{-5}$ & 02. 96 & 6 \\
\hline 45 & 51. 77 & b $14_{-14},-13-15_{-15},-14$ & 51. 8 & 19 & 25 & 03. 49 & a $14_{-10,-9}-15_{-11,-10}$ & 03. 60 & 16 \\
\hline & & $\mathrm{g} \quad 6_{-6}-7_{-7}$ & 51.8 & 2 & 35 & 05. 18 & d $\quad 7_{-7}-8_{-8}$ & 05. 16 & 2 \\
\hline 20 & 53. 19 & & & & 40 & 05.60 & a $14_{-12,},-11-15_{-13,-12}$ & 05.40 & 18 \\
\hline 20 & 53. 60 & & & & 30 & 06.60 & d $\quad 7_{-6}-8_{-7}$ & 06. 86 & 7 \\
\hline 28 & 54.35 & b $14_{-10,-9}-15_{-11,-10}$ & & 11 & 7 & 08. 43 & $3_{0}-4-1$ & 08. 11 & 1 \\
\hline 20 & 55. 72 & b $14_{-12},-11-15_{-13},-12$ & 55.93 & 16 & 8 & 08.58 & & & \\
\hline 30 & 57. 43 & & & & 9 & 08. 77 & & & \\
\hline 33 & 58. 84 & j $10_{-10,-9}-11_{-11},-10$ & 58.55 & 6 & 7 & 09.50 & $10_{-8}-11_{-9}$ & 09. 3 & 1 \\
\hline 33 & 59.91 & a $16-14,-13-11-11,-10$ & & 15 & 5 & 10. 08 & & & \\
\hline 17 & 60.95 & & & & 27 & 11. 03 & & & \\
\hline 42 & 61.54 & & & & 21 & 11.53 & $14_{0}-15_{-1}$ & 11. 53 & 6 \\
\hline 32 & 62.03 & & & & & & $11_{-4}-12_{-5}$ & 11. 62 & 11 \\
\hline 9 & 63.10 & & & & 23 & 11. 83 & $10_{-4}-11_{-5}$ & 11. 82 & 13 \\
\hline
\end{tabular}


TABLE 1. Emission lines in the region $1.9 \mu$ due to $\mathrm{H}_{2} \mathrm{O}$-Continued

\begin{tabular}{|c|c|c|c|c|c|c|c|c|c|c|c|}
\hline \multicolumn{2}{|c|}{ Observed } & \multicolumn{2}{|r|}{ Identification } & \multicolumn{2}{|c|}{ Calculated } & \multicolumn{2}{|c|}{ Observed } & \multicolumn{2}{|r|}{ Identification } & \multicolumn{2}{|c|}{ Calculated } \\
\hline $\begin{array}{l}\text { Inten- } \\
\text { sity }\end{array}$ & $\begin{array}{c}\text { Wave } \\
\text { number } \\
\nu_{\mathrm{v} \text { ae }}\end{array}$ & & $J^{\prime} \tau-J^{\prime \prime} \tau$ & $\begin{array}{c}\text { Wave } \\
\text { number } \\
\nu_{\text {vac }}\end{array}$ & $\begin{array}{c}\text { Intensity } \\
\left(\sim 2,877^{\circ} \mathrm{K}\right)\end{array}$ & $\begin{array}{l}\text { Inten- } \\
\text { sity }\end{array}$ & $\begin{array}{c}\text { Wave } \\
\text { number } \\
\nu_{\mathrm{vac}}\end{array}$ & & $J^{\prime} \tau-J^{\prime \prime} \tau$ & $\begin{array}{c}\text { Wave } \\
\text { number } \\
\nu_{\text {vac }}\end{array}$ & $\begin{array}{l}\text { Intensity } \\
\left(\sim 2,877^{\circ} \mathrm{K}\right)\end{array}$ \\
\hline 21 & $\begin{array}{l}c m^{-1} \\
12.39\end{array}$ & $\mathrm{e}$ & $10_{-10,-9}-11_{-11,-10}$ & $\begin{array}{l}c m^{-1} \\
12.39\end{array}$ & 6 & 85 & $\begin{array}{c}c m^{-1} \\
5049.65\end{array}$ & a & $12_{-12,-11}-13_{-13,-12}$ & $\begin{array}{l}c m^{-1} \\
49.54\end{array}$ & 23 \\
\hline & & & $15_{2,3}-16_{1,2}$ & & 6 & & & $\mathrm{c}$ & $7_{-2}^{-11}-8_{-3}$ & 49. 65 & 9 \\
\hline 23 & 13. 21 & a & $13_{-7}-14_{-8}$ & 13. 11 & 4 & & & e & $8_{-1}-9_{-2}$ & 49. 79 & 1 \\
\hline 15 & 14. 11 & & & & & & & & $12_{-10,-9}-13_{-11,-10}$ & 49.90 & 20 \\
\hline & 14. 79 & $\begin{array}{l}\mathrm{b} \\
\mathrm{a}\end{array}$ & $\begin{array}{l}11_{-6}-12_{-7} \\
13_{-4}-14_{-5}\end{array}$ & $\begin{array}{l}\text { 14. } 77 \\
14.86\end{array}$ & $\begin{array}{r}13 \\
9\end{array}$ & & & & & & \\
\hline 35 & 16. 86 & c & $9_{-9,-8}-10_{-10,-9}$ & 16. 78 & 15 & $* 10$ & 5280.59 & & & & \\
\hline 14 & 17. 94 & $\begin{array}{l}\text { f } \\
\text { g }\end{array}$ & $\begin{array}{c}10_{-2}-11_{-3} \\
5_{0}-6-1 \\
2_{0}-3_{1}\end{array}$ & $\begin{array}{l}\text { 16. } 92 \\
\text { 17. } 78 \\
\text { 18. } 09\end{array}$ & $\begin{array}{r}11 \\
2 \\
1\end{array}$ & $\begin{array}{l}15 \\
15 \\
25\end{array}$ & $\begin{array}{l}81.09 \\
81.64 \\
82.21\end{array}$ & c & $9_{3,2}-9_{2,3}$ & $\ldots \ldots$ & 8 \\
\hline 17 & 18. 75 & $\hat{\mathrm{f}}$ & $5_{-2}-6-3$ & 18. 71 & 2 & 25 & 82. 44 & c & $8_{4,3}-8_{3,4}$ & $\ldots$ & 10 \\
\hline 14 & 19.65 & a & $15_{4,5}-16_{3,4}$ & & 5 & 30 & 84. 06 & c & $7_{4,5}-7_{5,4}^{5,4}$ & & 13 \\
\hline & & a & $17_{-14}-17_{-13}$ & 19.5 & 1 & $* 32$ & 85. 22 & d & $6-6-5_{-5}$ & 5284.91 & 5 \\
\hline 31 & 20.54 & a & $12_{-4}-13_{-5}$ & 20. 32 & 12 & & & $\mathrm{k}$ & $9_{-y}-8_{-8}$ & 84.96 & 3 \\
\hline & & a & $13_{-2}-14_{-3}$ & 20. 32 & 9 & & & d & $4_{0}-3_{1}$ & 85. 12 & 3 \\
\hline 43 & 20.90 & $b$ & $\begin{array}{l}11_{-8}-12_{-9} \\
13_{-6}-14_{-7}\end{array}$ & $\begin{array}{l}20.68 \\
20.90\end{array}$ & 14 & & & c & $3_{-2}-2_{-1}$ & 85. 31 & 5 \\
\hline & & a & $\begin{array}{l}13_{-6}-14_{-7} \\
12_{-2}-13_{-3}\end{array}$ & $\begin{array}{l}20.90 \\
21.19\end{array}$ & $\begin{array}{l}12 \\
12\end{array}$ & 30 & 86.25 & $\begin{array}{l}c \\
b\end{array}$ & $\begin{array}{c}6_{6,5}-6_{5,6} \\
2_{2}-2_{1}\end{array}$ & $\begin{array}{l}85.87 \\
85.91\end{array}$ & $\begin{array}{r}16 \\
8\end{array}$ \\
\hline 44 & 23. 07 & $\mathrm{~b}$ & $11_{-11,-10}-12_{-12,-11}$ & 23. 01 & 22 & 22 & 86.81 & a & $11_{-4}-11_{-3}$ & 86. 76 & 2 \\
\hline 20 & 23. 70 & a & $14_{2}-15_{1}$ & & 6 & 17 & 87. 29 & $\mathrm{e}$ & $7_{5,4}-7_{4,5}$ & & 5 \\
\hline 27 & 24. 21 & a & $13_{-9}-14_{-10}$ & 24. 27 & 4 & 17 & 87. 74 & $\mathrm{e}$ & $6_{6,5}-6,6$ & 87.74 & 7 \\
\hline & & a & $13_{-8}-14_{-9}$ & 24. 44 & 12 & 20 & 88. 44 & $\mathrm{c}$ & $3_{-3}-2$ & 88. 25 & 2 \\
\hline 25 & 25. 12 & d & $6_{-6}-7_{-7}$ & 24.55 & 6 & 16 & 89.19 & b & $5_{0}-5_{1}$ & $\begin{array}{l}88.37 \\
80.38\end{array}$ & 6 \\
\hline 45 & 25. 47 & a & $13_{-13,-12}-14_{-14,-13}$ & 25. 46 & 22 & $\begin{array}{l}10 \\
17\end{array}$ & $\begin{array}{l}\text { 89. } 19 \\
90.14\end{array}$ & a & $\begin{array}{r}2-1-1 \\
1_{0}-2_{-1}\end{array}$ & $\begin{array}{l}89.20 \\
90.28\end{array}$ & 4 \\
\hline 30 & 26. 40 & $\mathrm{~b}$ & $10_{-6}-11_{-7}$ & 26.5 & 13 & 25 & 91. 29 & $\mathrm{f}$ & $8_{-8}-7-7$ & 91.24 & 3 \\
\hline 40 & 27. 36 & $\mathrm{f}$ & $5_{-4}-6-5$ & 27. 19 & 2 & & & $\mathrm{f}$ & $6-4-5-3$ & 91. 29 & 2 \\
\hline & & a & $13_{-11,-10}-14_{-12,-11}$ & 27. 2 & 19 & 30 & 93.07 & $\mathrm{c}$ & $86,5-85,0$ & & 13 \\
\hline & & d & $6_{-5}-7_{-6}$ & 27. 25 & 1 & 47 & 94. 32 & $\mathrm{~b}$ & $3_{2}-3_{3}$ & 93.93 & 12 \\
\hline & & $\mathrm{g}$ & $2_{-2}-3-3$ & 27.52 & 1 & & & b & $3_{3}-3_{2}$ & 94.07 & 4 \\
\hline 20 & 29.26 & $\mathrm{e}$ & $9_{-7}-10_{-8}$ & 29. 20 & 4 & & & b & $4_{2}-4_{1}$ & 94.43 & 9 \\
\hline 25 & 29.73 & $\mathrm{f}$ & $5_{2}-6_{1}$ & 29.88 & 1 & 41 & 94.87 & $\mathrm{c}$ & $7_{7,6}-7_{6,7}$ & & 16 \\
\hline & & $\mathrm{f}$ & $4_{-2}-5-3$ & 30.05 & 2 & 13 & 95. 73 & b & $2_{0}-2$ & 95.68 & 2 \\
\hline 20 & 31.50 & a & $11_{-3}-12_{-4}$ & 31.53 & 4 & 15 & 96.50 & b & $5_{1}-5_{0}$ & 96. 51 & 2 \\
\hline 10 & 33.47 & & & & & 15 & 97. 26 & b & $4_{0}-4_{-1}$ & 97. 31 & 4 \\
\hline 13 & 34. 65 & & & & & 13 & 97. 97 & d & $4_{2}-3_{3}$ & 97. 61 & 1 \\
\hline 16 & 34. 99 & $\mathrm{e}$ & $9_{-9,-8}-10_{-10, \sim 9}$ & 35.01 & 7 & & & $\mathrm{e}$ & $9_{5,4}-9_{4,5}$ & & 5 \\
\hline 10 & 35.53 & & & & & 14 & 98.52 & e & $2_{0}-1_{1}$ & 98. 41 & 1 \\
\hline 15 & 35. 97 & & & & & & & e & $8_{6,5}-8_{5,6}$ & & 6 \\
\hline 20 & 36.70 & a & $13_{1}-14_{0}$ & $-\cdots$ & 2 & 32 & 99.28 & d & $5_{-2}-4-1$ & 99.22 & 5 \\
\hline & & a & $14_{3,4}-15_{2,3}$ & $\ldots \ldots$ & 6 & & & e & $77,6-7_{6,7}$ & 99. 26 & 7 \\
\hline 32 & 37. 91 & $\mathrm{~b}$ & $10_{0}-11_{-1}$ & & 10 & & 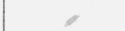 & d & $7_{-6}-6_{-5}$ & 99.44 & 6 \\
\hline & & c & $8_{-8,-7}-9_{-9,-8}$ & 37. 88 & 14 & & & b & $7_{0}-7_{1}$ & 99. 64 & 7 \\
\hline & & a & $13_{0}-14_{-1}$ & 38. 06 & 6 & $* 19$ & 5300.23 & a & $3_{-2}-3_{-1}$ & 99.77 & 2 \\
\hline 20 & 40.13 & & & & & & & $\mathrm{k}$ & $10_{-10,-9}-9_{-9,-8}$ & 5300.0 & 4 \\
\hline 28 & 40. 61 & f & $4_{2}-5_{1}$ & 40. 48 & 1 & & & d & $7_{-7}-6_{-6}$ & 00.25 & 2 \\
\hline & & b & $10_{-8}-11_{-9}$ & 40. 69 & 15 & 23 & 02.05 & b & $6_{0}-6_{-1}$ & 02.15 & 5 \\
\hline & & $\mathrm{a}$ & $12_{-3}-13_{-4}$ & 40.88 & 4 & 52 & 04. 48 & $\mathrm{~b}$ & $6_{2}-6_{1}$ & 04.17 & 13 \\
\hline & & a & $12_{-5}-13_{-6}$ & 40.90 & 4 & & & $\mathrm{f}$ & $6-2-5-1$ & 04.32 & 2 \\
\hline 8 & 41. 71 & $\mathrm{~b}$ & $10_{-7}-11_{-8}$ & 41.55 & 5 & & & $\mathrm{~b}$ & $5_{3,2}-5_{2,3}$ & 04.58 & 15 \\
\hline 10 & 42.03 & & & & & & & b & $7_{1}-7_{0}$ & 04.84 & 2 \\
\hline 21 & 43. 26 & d & $5_{-5}-6_{-6}$ & 42. 82 & 5 & & & $\mathrm{c}$ & $3-1-2$ & 04.84 & 2 \\
\hline 35 & 43.77 & a & $12_{0}-13_{-1}$ & 43. 39 & 9 & 55 & 05.57 & $\mathrm{f}$ & $9_{-9,-8}-8_{-8,-7}$ & 05.60 & 4 \\
\hline & & a & $12_{-8}-13_{-9}$ & 43. 70 & 12 & & & $\mathrm{e}$ & $3-2-2_{1}$ & 05.62 & 2 \\
\hline & & d & $4-2-5-3$ & 43. 71 & 5 & & & b & $4_{4,3}-4_{3,4}$ & 05.68 & 20 \\
\hline 27 & 44.28 & d & $5_{-2}-6_{-3}$ & 44. 08 & 5 & 20 & 06. 30 & $\mathrm{c}$ & $4_{-4}-3-3$ & 06.27 & 6 \\
\hline & & a & $12_{-7}-13_{-6}$ & 45. 17 & 4 & $* 16$ & 08. 29 & b & $8_{0}-8_{-1}$ & 08.53 & 5 \\
\hline & & a & $14_{5,6}-15_{4,5}$ & 44. 59 & 5 & 7 & 08.98 & $\mathrm{c}$ & $33_{1}-4_{0}$ & 08.95 & 2 \\
\hline 45 & 45. 79 & $\mathrm{~b}$ & $10_{-10,-9}-11_{-11,-10}$ & 45. 64 & 22 & 15 & 09. 66 & $\mathrm{e}$ & $9_{7,6}-9_{6,7}$ & & 6 \\
\hline & & f & $4_{-4}-5_{-5}$ & 46. 05 & 2 & & & a & $10_{-3}-10_{-2}$ & 09.77 & 1 \\
\hline & & a & $11_{-5}-12_{-6}$ & 46. 06 & 4 & 16 & 10.80 & $\mathrm{e}$ & $8_{8,7}-8_{7,8}$ & & 7 \\
\hline 21 & 46. 66 & $\mathrm{e}$ & $8_{-3}-9_{-4}$ & 46. 42 & 4 & 9 & 11. 70 & $\mathrm{f}$ & $6_{2}-5_{3}$ & 11.73 & 1 \\
\hline 15 & 47. 45 & $\mathrm{e}$ & $7_{-3}-8_{-4}$ & 47. 41 & 4 & & & $\mathrm{~b}$ & $3_{-1}-3_{-2}$ & 11. 81 & 2 \\
\hline & & d & $5_{-4}-66_{-5}$ & 47.51 & 6 & 9 & 12.15 & & & & \\
\hline & & a & $12_{-1}-13_{-2}$ & 47.55 & 3 & 32 & 13. 46 & a & $13_{-4}-13_{-3}$ & 12. 82 & 1 \\
\hline 12 & 48. 72 & a & $13_{2,3}-14_{1,2}$ & 49. 2 & 8 & & & b & $8_{1}-8_{2}$ & 13. 25 & 3 \\
\hline
\end{tabular}


TABLE 1. Emission lines in the region $1.9 \mu$ due to $\mathrm{H}_{2} \mathrm{O}$-Continued

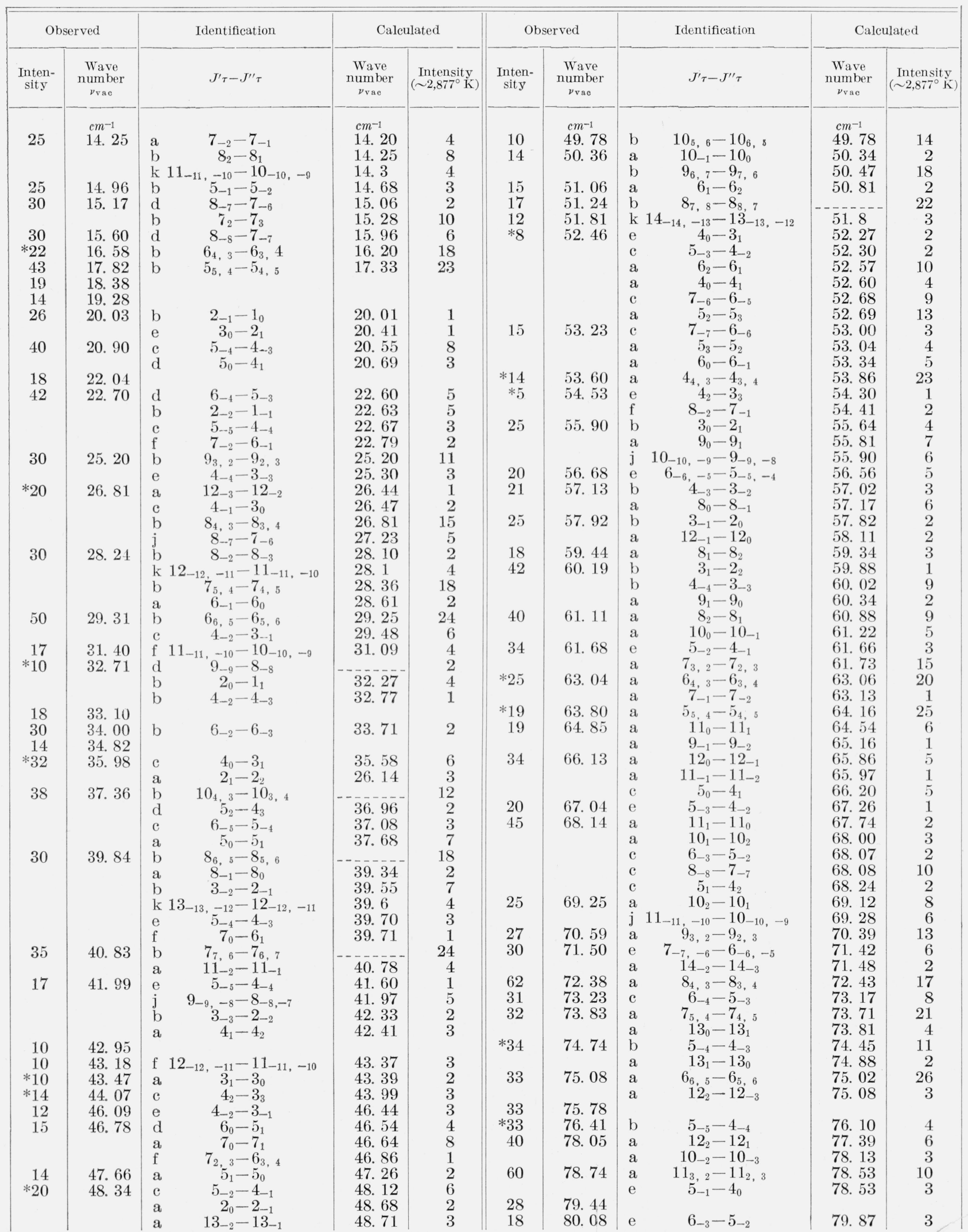


TABLE 1. Emission lines in the region $1.9 \mu$ due to $\mathrm{H}_{2} \mathrm{O}$-Continued

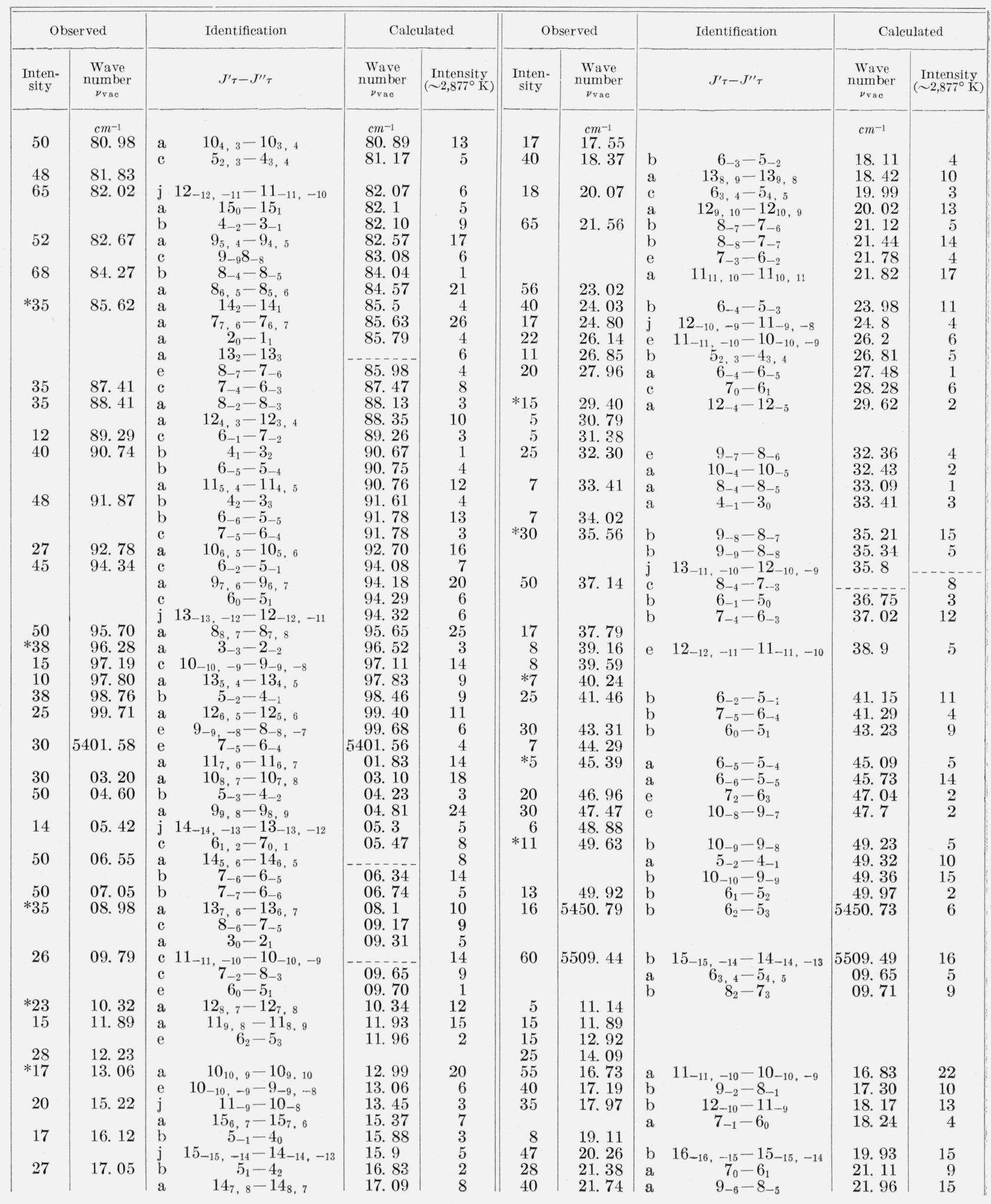


TABLE 1. Emission lines in the region $1.9 \mu$ due to $\mathrm{H}_{2} \mathrm{O}$-Continued

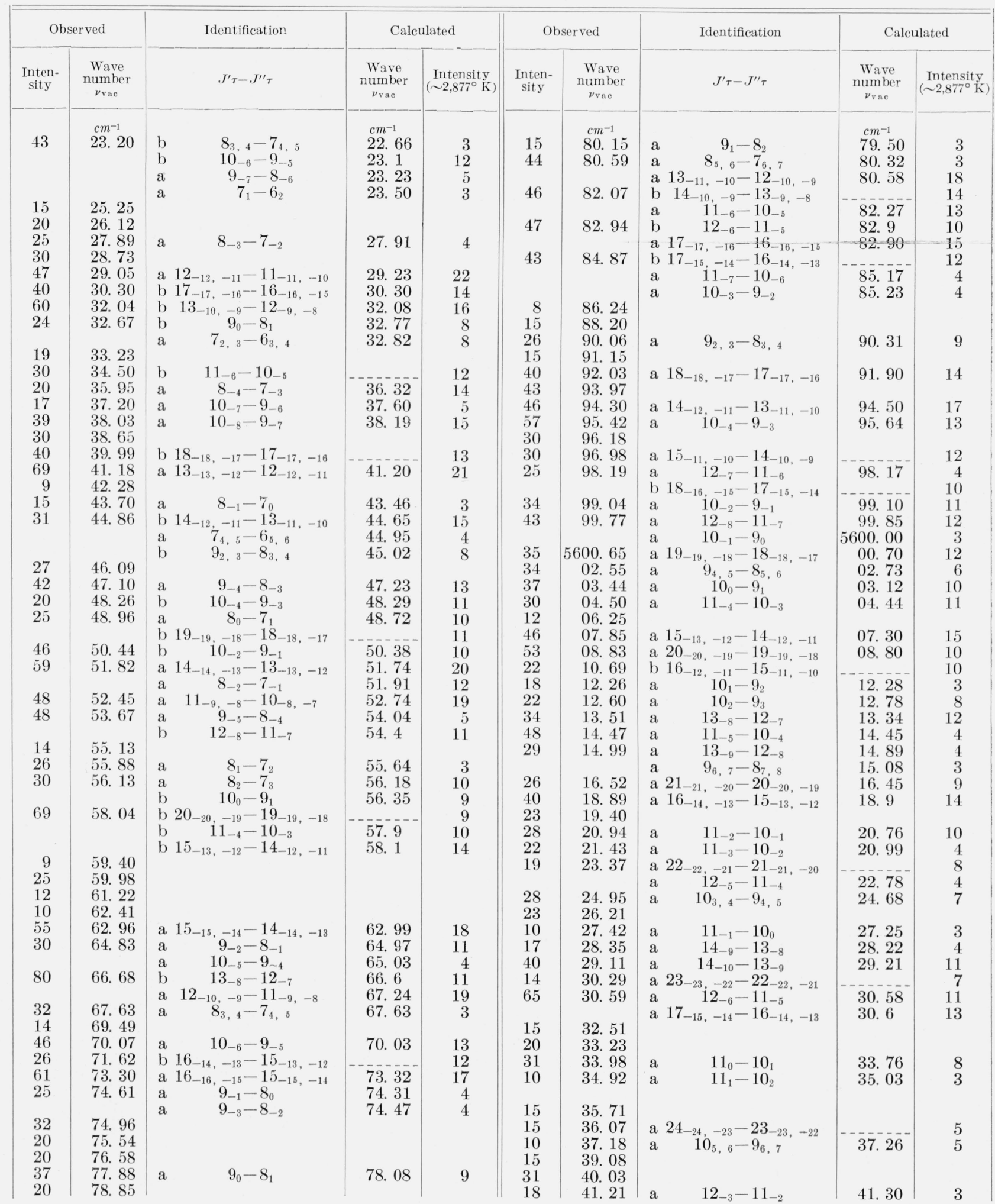


TABLE 1. Emission lines in the region $1.9 \mu$ due to $\mathrm{H}_{2} \mathrm{O}$-Continued

\begin{tabular}{|c|c|c|c|c|c|c|c|c|c|}
\hline \multicolumn{2}{|c|}{ Observed } & \multirow{2}{*}{$\begin{array}{l}\text { Identification } \\
J^{\prime} \tau-J^{\prime \prime} \tau\end{array}$} & \multicolumn{2}{|c|}{ Calculated } & \multicolumn{2}{|c|}{ Observed } & \multirow{2}{*}{$\begin{array}{l}\text { Identification } \\
\qquad J^{\prime} \tau-J^{\prime \prime} \tau\end{array}$} & \multicolumn{2}{|c|}{ Calculated } \\
\hline $\begin{array}{l}\text { Inten- } \\
\text { sity }\end{array}$ & $\begin{array}{c}\text { Wave } \\
\text { number } \\
\nu_{\mathrm{vac}}\end{array}$ & & $\begin{array}{c}\text { Wave } \\
\text { number } \\
\nu_{\mathrm{vac}}\end{array}$ & $\begin{array}{c}\text { Intensity } \\
\left(\sim 2,877^{\circ} \mathrm{K}\right)\end{array}$ & $\begin{array}{l}\text { Inten- } \\
\text { sity }\end{array}$ & $\begin{array}{c}\text { Wave } \\
\text { number } \\
\nu_{\mathrm{vac}}\end{array}$ & & $\begin{array}{c}\text { Wave } \\
\text { number } \\
\nu_{\mathrm{vac}}\end{array}$ & $\begin{array}{l}\text { Intensity } \\
\left(\sim 2,877^{\circ} \mathrm{K}\right)\end{array}$ \\
\hline $\begin{array}{r}16 \\
42 \\
30 \\
27 \\
10 \\
22 \\
43 \\
\\
5\end{array}$ & $\begin{array}{l}c m^{-1} \\
42.02 \\
\\
44.65 \\
45.77 \\
46.86 \\
47.03 \\
49.30 \\
51.68 \\
53.30\end{array}$ & $\begin{array}{lc}\text { a } & 13_{-6}-12_{-5} \\
\text { a } & 18_{-16,-15}-17_{-15,-14} \\
\text { a } & 15_{-11,-10}-14_{-10,-9} \\
\text { a } & 11_{2,3}-10_{3,4} \\
\text { a } & 13_{-7}-12_{-6} \\
& \\
\text { a } & 10_{7,8}-9_{8,9} \\
\text { a } & 12_{-2}-11_{-1} \\
\text { a } & 19_{-17}-16-18_{-16,-15} \\
\text { a } & 12_{-1}-11_{0} \\
& \\
\text { a } & 12_{-4}-11_{-3} \\
\text { a } & 12_{0}-11_{1} \\
\text { a } & 13_{-4}-12_{-5} \\
& \\
\text { a } & 11_{4}, 5-10_{5,6} \\
\text { a } & 14_{-7}-13_{-6} \\
\text { a } & 16_{-12,-11}-15_{-11,-10}\end{array}$ & $\begin{array}{l}c m^{-1} \\
41.56 \\
42.0 \\
44.37 \\
46.20 \\
46.91 \\
\text { 49. } 13 \\
51.39 \\
52.94\end{array}$ & $\begin{array}{r}10 \\
11 \\
13 \\
8 \\
4 \\
\\
2 \\
10 \\
10 \\
3\end{array}$ & $\begin{array}{r}5 \\
6 \\
17 \\
9 \\
20 \\
32 \\
27 \\
10 \\
27 \\
\\
20 \\
16 \\
34 \\
10 \\
25\end{array}$ & $\begin{array}{l}\mathrm{cm}^{-1} \\
61.52 \\
62.89 \\
63.63 \\
64.75 \\
65.60 \\
66.68 \\
67.45 \\
68.35 \\
71.34 \\
73.29 \\
74.04 \\
74.82 \\
78.01 \\
79.80\end{array}$ & $\begin{array}{lc}\text { a } & 12_{1,2}-11_{2,3} \\
\text { a } & 11_{6,7}-10_{7,8} \\
\text { a } & 13_{-2}-12_{-1} \\
& \\
\text { a } & 21_{-19,-18}-20_{-18,-17} \\
\text { a } & 17_{-13,-12}-16_{-12,-11} \\
& \\
\text { a } & 15_{-8}-14_{-7} \\
\text { a } & 12_{3,4}-11_{4,5} \\
\text { a } & 11_{8,9}-10_{9,10} \\
\text { a } & 22_{-20,-19}-21_{-19,-18}\end{array}$ & $\begin{array}{l}74.0 \\
79.70 \\
79.83 \\
82.9\end{array}$ & $\begin{array}{r}9 \\
4 \\
8 \\
6 \\
11 \\
\\
9 \\
7 \\
2 \\
5\end{array}$ \\
\hline
\end{tabular}

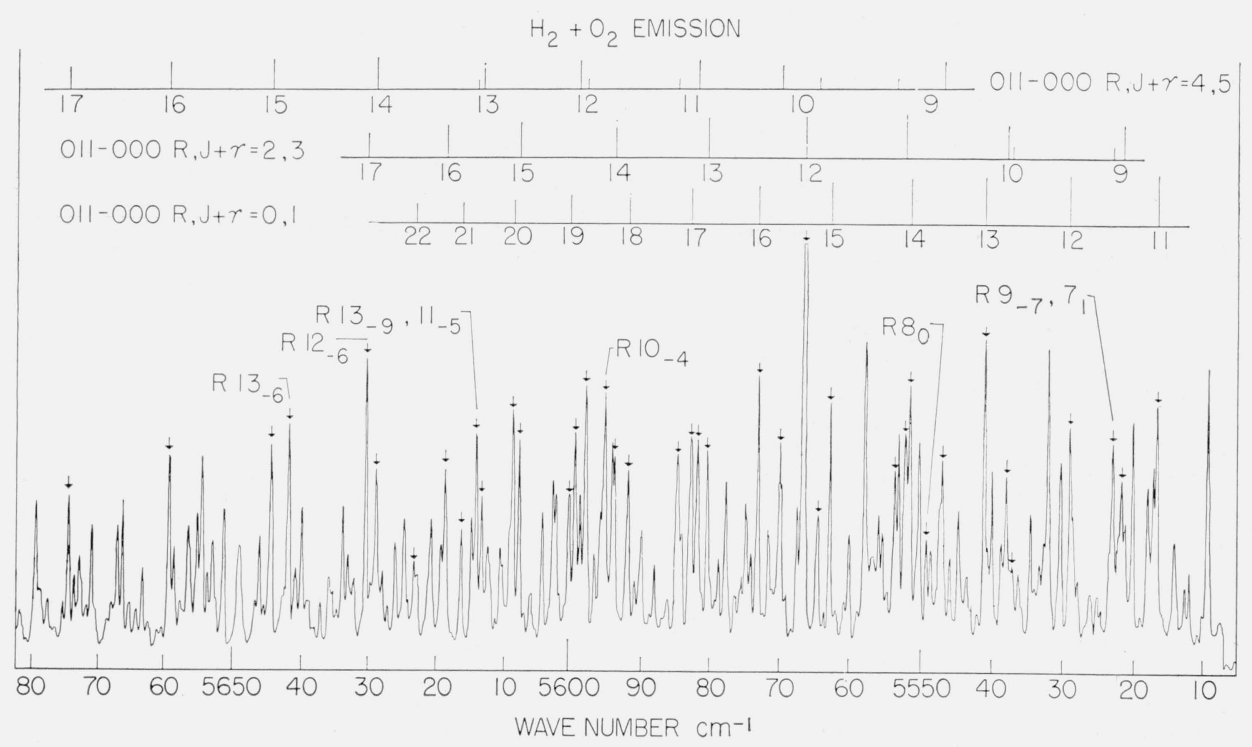

Figure 1. Emission spectrum of $\mathrm{H}_{2} \mathrm{O}$ in the region 5,510 to $5,680 \mathrm{~cm}^{-1}$.

the analysis has accounted for most of the expected transition intensity, and it is believed that a major fraction of the measured lines are single lines whose position and intensity will not be appreciably altered under higher resolution.

Tracings of the observed emission, in three regions which best illustrate the nature of the spectrum and its analysis, are presented in figures 1 to 3 . These are tracings of the spectrum to which have been added wave-number scales and various identifying marks pointing out some of the strongest series. The spectra show the degree of resolution, and discrimination between strong and weak lines, that has been achieved. Figure 1 covers the region 5,055 to $4,908 \mathrm{~cm}^{-1}$, which includes the strongest lines in the $P$ branch of the (011-000) and upperstate bands. It is a region where atmospheric absorption is negligible. Figure 2, covering the region 5,450 to $5,280 \mathrm{~cm}^{-1}$, shows how lines of the Q branch, which would normally be strong, are reduced in intensity by the atmospheric absorption. The strongest dips in the base line are also due to atmospheric absorption, as may be verified by comparison with the spectra in Nelson's report [5]. In 


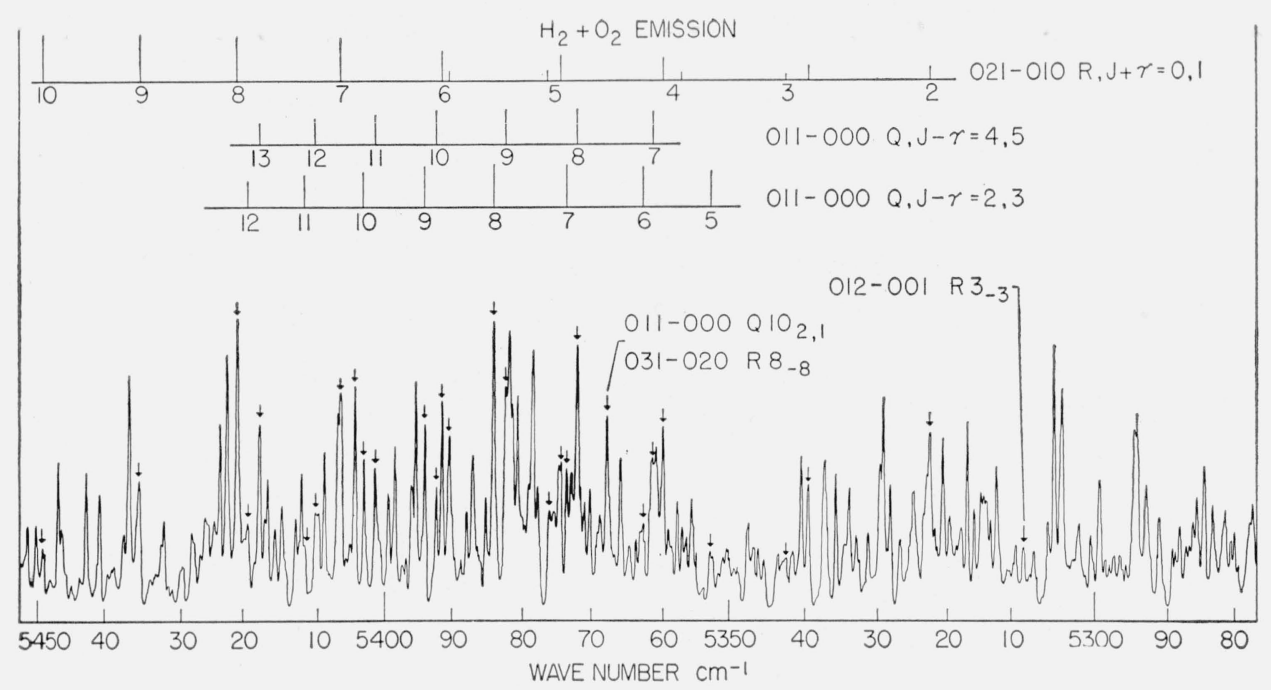

Figure 2. Emission spectrum of $\mathrm{H}_{2} \mathrm{O}$ in the region 5,280 to $5,450 \mathrm{~cm}^{-1}$.

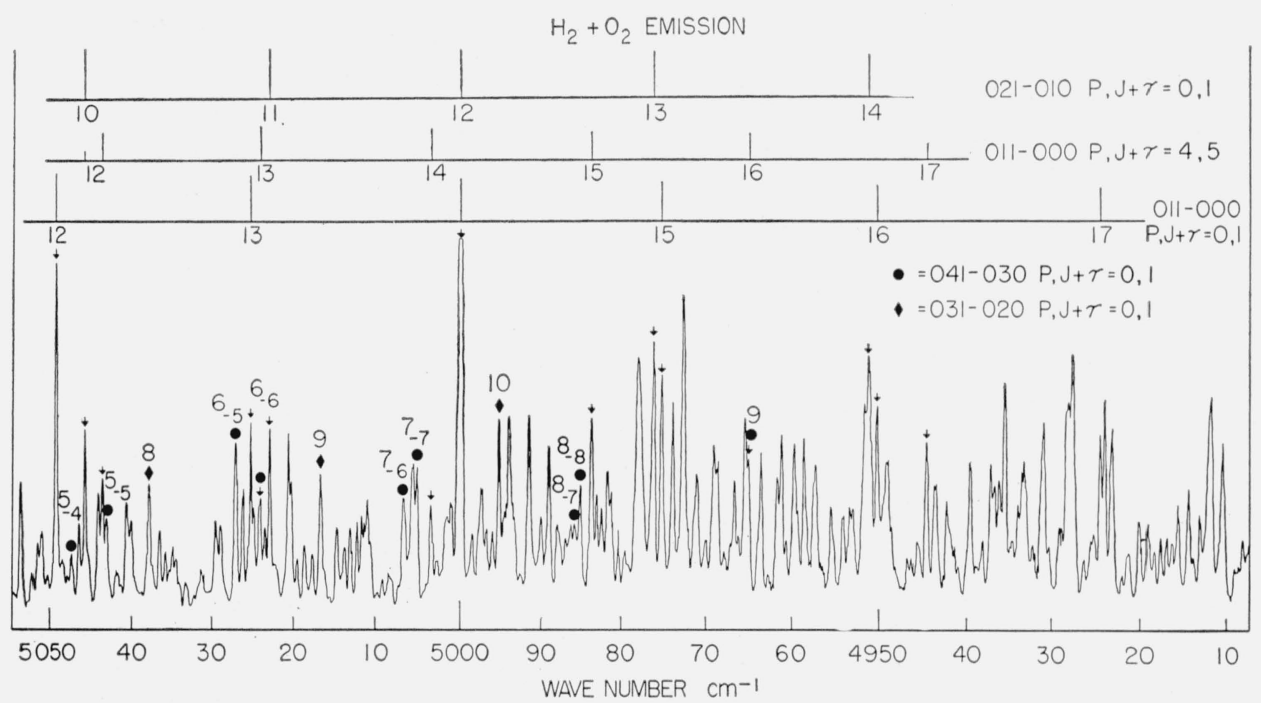

Figure 3. Emission spectrum of $\mathrm{H}_{2} \mathrm{O}$ in the region 4,910 to $5,050 \mathrm{~cm}^{-1}$.

figure 3 , covering the region 5,680 to $5,510 \mathrm{~cm}^{-1}$, lines of the $R$ branches of the (011-000) band appear essentially free from atmospheric absorption. These three figures include the region of strongest emission; at frequencies greater than $5,680 \mathrm{~cm}^{-1}$ and less than $4,910 \mathrm{~cm}^{-1}$ the intensity falls off gradually. In the intermediate region 5,280 to $5,055 \mathrm{~cm}^{-1}$ the emission is weak, since it lies near the band origins, and is further reduced by atmospheric absorption.

\section{Discussion}

The absorption spectrum of $\mathrm{H}_{2} \mathrm{O}$, both in the region of $1.9 \mu$ now under consideration, and throughout the rotation-vibration spectrum extending from the microwave region $\left(0.74 \mathrm{~cm}^{-1}\right)$ to the green visible $\left(18,500 \mathrm{~cm}^{-1}\right)$, is well understood and quite completely analyzed. The water-vapor molecule is an asymmetric-top rotator with effective reciprocal moments of inertia, which in the ground vibrational state have the values $A=27.877 \mathrm{~cm}^{-1}, B=14.512$ $\mathrm{cm}^{-1}, C=9.285 \mathrm{~cm}^{-1}$, leading to an asymmetry parameter $k=-0.4377$. It has three fundamental frequencies of vibration, two preserving the molecular symmetry $\nu_{1}=3,657.05 \mathrm{~cm}^{-1}$, and $\nu_{2}=1,594.59$ $\mathrm{cm}^{-1}$, and the third in which the motion of the $\mathrm{H}$ atoms is antisymmetric to the symmetry axis, $\nu_{3}=3,755.79 \mathrm{~cm}^{-1}$. In the absorption spectrum, transitions occur from the ground vibrational level to these three fundamentals, and to a very large 
number of the possible overtones and combinations of them; in all, 43 bands have been observed. Many of these, however, are quite weak; in particular, transitions to levels in which $v_{3}$ is even are very much less intense than those in which $v_{3}$ is odd. For example, in the $1.9-\mu$ region, there are the two bands $(011-000)$, whose origin is at $5,331.19 \mathrm{~cm}^{-1}$, and $(110-000)$, whose origin is at $5,235.0 \mathrm{~cm}^{-1}$; the latter is only about one thirtieth as strong as the former, and hence plays a very minor role in the absorption and cannot be detected in emission. ${ }^{5}$

In each band with $\Delta v_{3}=$ odd, the rotational structure is similar (except for differences resulting from the different values of $A^{\prime}-A^{\prime \prime}, B^{\prime}-B^{\prime \prime}$, and $C^{\prime}-C^{\prime \prime}$ involved); namely, there are four strong branches, the relative intensity of whose lines may be calculated according to the methods of Cross, Hainer, and King [10]. The $R_{01}$ and $P_{01}$ branches extend, respectively, to higher and lower frequencies from the origin, and each consists of one line for each rotational level $J_{\tau}^{\prime}(-J \leqq \tau \leqq J)$. The $Q_{01}$ and $Q_{10}$ branches fall near the origin (in the $1.9-\mu$ band, where $A^{\prime}-A^{\prime \prime}$ is positive, they lie mostly at frequencies higher than the origin), and together contribute one line for each $J_{\tau}^{\prime} . \quad\left(Q_{01}\right.$ for $J-\tau$ even; $Q_{10}$ for $J-\tau$ odd). The intensity of an emission line is given by the formula $I=\nu^{4} T_{0} g e^{-E^{\prime} / k T}$, (in absorption, the formula is the same, except that $\nu^{4}$ becomes $\nu$, and $E^{\prime}$ becomes $\left.E^{\prime \prime}\right) . \quad L$ is the line strength, a number such that for each $J_{\tau}^{\prime}, \Sigma L=2 J^{\prime}+$ 1 ; for $\tau \sim-J, L \sim J$ for $R_{01}$ and $P_{0 \overline{1}}$, and $L \sim 0$ for the $Q$ lines; for $\tau \sim+J, L \sim 0$ for $R$ and $P$, and $\sim 2 J$ for $Q$, with a gradual transition between these limits for intermediate $\tau$. Since $E^{\prime}$ increases rapidly with $\tau$ for a given $J$, the intensity of the $R$ and $P$ lines falls off rapidly as $J+\tau$ increases. Since the Boltzmann factor and $L$ oppose each other for $Q$ lines, there are several lines of nearly equal intensity for each $J$, those with $J-\tau$ low. Another term in the intensity formula is the nuclear spin factor $g$, which is 3 for $\tau$ odd, 1 for $\tau$ even; hence the former lines are predominant. The final factor in the intensity is the vibrational transition probability $T_{v}$, which in first approximation should be constant for all lines of a band, but which in some bands of $\mathrm{H}_{2} \mathrm{O}$ (but not 011-000) shows anomalies favoring one branch over another.

The absorption spectrum in the $1.9-\mu$ region is fully in accord with the above formula. It has been possible to identify all the lines down to those of quite low intensity, comprising the strong series $R_{01}, P_{01}, Q_{01}$, and $Q_{10}$ for $E^{\prime \prime} \leqq 2,000 \mathrm{~cm}^{-1}$. In addition, there have been observed lines of the series $R_{2 \overline{1}}, P_{\overline{2} 1}$, and $Q_{1 \overline{2}}$, and $Q_{2 \overline{1}}$ (these have much lower $L$ but can be observed in the terrestrial atmosphere, since the first two series lie at the extreme wings of the band) and, as was mentioned above, lines of the 110-000 band, which follow different selection rules, but which are all weak because they have a different and much lower $T_{v}$.

\footnotetext{
${ }^{5}$ An exception to this statement holds for a few rotational levels of 110 , which accidentally lie close in energy to levels of 011 of equal $J$ and like total symmetry; transitions to these are strengthened by perturbation induced by Coriolis forces.
}

It is to be expected, and it has been found, that the emission spectrum differs from the absorption spectrum only as a result of the much higher value of temperature in the Boltzmann factor term of the intensity formula.

The levels of higher energy that are sufficiently populated in the flame to emit with considerable intensity manifest themselves in two different ways. First, rotational levels of higher $J_{\tau}^{\prime}$ will be populated, the fact that $L$ increases along with $J$ further augmenting the intensity of lines from such levels. Hence, the (011-000) band will show many new lines, especially in the long-wavelength ( $P$ branch) and short-wavelength ( $R$ branch) wings of the band. Second, higher vibrational levels, particularly the lowest ones involving $\nu_{2}$, will be populated; since $T_{v}$, for transitions with $\Delta \nu_{2}=1$, increases proportionally with $\nu_{2}^{\prime}$, the intensity of all rotational transitions in such bands as (021-010), (031-020), etc., will be appreciable relative to (011-000) at flame temperatures. These new "upper-state" bands will form sequences of decreasing intensity at longer wavelengths and hence will be more prominent in the $P$ branches than in the $R$, where many of their lines will fall in the region of atmospheric absorption.

A rough quantitative calculation of the expected relative intensities at flame temperatures has been made as a guide in the analysis of the new emission lines. For this purpose $T$ was chosen at $2,877^{\circ} \mathrm{K}$ $\left(k T=2,000 E^{\prime}\right) . \quad L$ values were obtained for $J \leqq 12$ from the tables of Cross, Hainer, and King [10], interpolated to $k=-0.437$. For $J>12, L$ was estimated by extrapolation of those tables, making use of the facts that the relative total intensities of the several branches are smooth functions of $J$, that the distribution of intensity within each branch at any $J$ as a function of $\tau / J$ is roughly the same, and that the sum rules given in [10] must be obeyed. The resulting $L$ values may be in error by as much as 10 percent at $J=20$, but should be adequate for showing the trends of intensity. The energies for the Boltzmann factor were in part those observed (see table 4), and in part were estimated for unobserved levels by extrapolation. The resulting relative intensities, for lines of the $P_{0 \mathrm{1}}$ branch, are presented in table 2 . The intensity factors, $g L e^{-E / k T}$, are given in a rectangular array, with $J^{\prime}$ vertical and $(J+\tau)$ horizontal. There are a number of cases, for high $J+\tau$, and for low $J+\tau$ at high $J$, where lines of odd and even $\tau$ fall in unresolvable pairs; these are combined in table 2 , and may be recognized, inasmuch as the $3: 1$ intensity alternation due to the nuclear-spin factor is absent. Similar calculations of intensities in the $R_{01}, Q_{10}$, and $Q_{01}$ branches (of which the two latter also coalesce at high $J+\tau$ ) have also been made. The calculated intensities, as listed for identified lines in the last column of table 2 , are these rotational intensity factors for the case of the $011-000$ band (band $a$ ). For other vibrational transitions, an additional vibrational intensity factor must be included. 


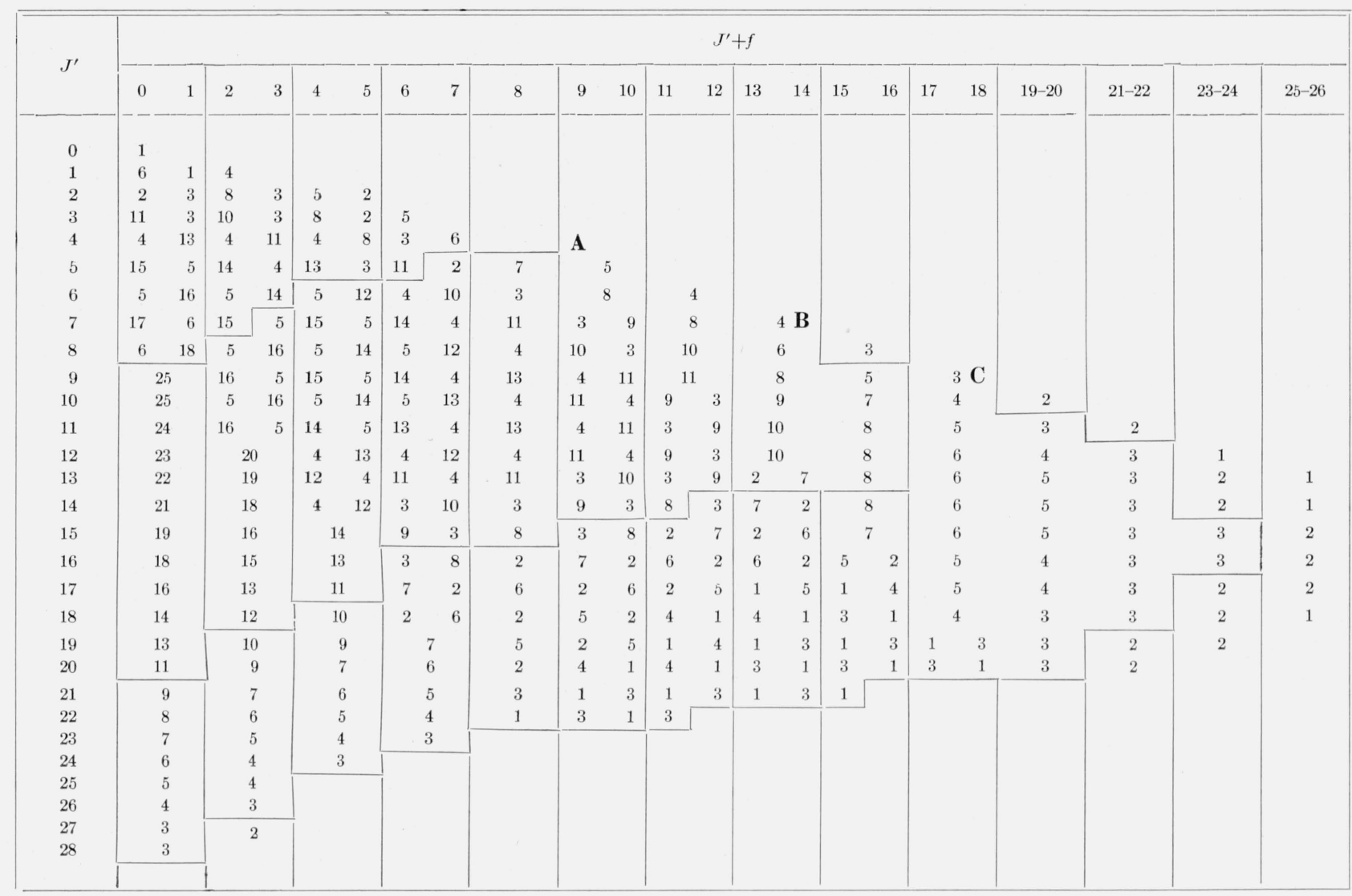

$\mathbf{A}, 287^{\circ} ; \mathbf{B}, 1,438^{\circ} ; \mathbf{C}, 2,877^{\circ} \mathrm{K}$.

In table 2 a solid line has been drawn to delimit the range of $J_{\tau}$ values yielding $P_{\overline{01}}$ intensities up to 10 percent of that of the maximum. It is not to be expected that lines weaker than this could be identified under the experimental conditions. A large proportion of the lines within this limit have been found, the exceptions being principally among the levels of intermediate $\tau$ for which the energy does not vary with $J$ and $\tau$ in as regular a manner as when $\tau \sim-J$ or $\tau \sim+J$. The two other lines in table 2 at lower $J$ similarly delimit the 10 percent of maximum-intensity range for two lower temperatures, $1,438^{\circ}$ and $287^{\circ} \mathbf{K}$, and illustrate how the increase in temperature results in the appearance of many new rotational transitions.

The relative rotational intensities within the various upper state bands will be nearly the same as for 011-000, small differences arising from the different energies relative to the $J=0$ level. However, these may be ignored for the rough calculations made here. Table 3 gives the band origins and the relative intensities of the stronger expected bands, $I_{2877}=T_{v} e^{-\left(E_{v}-E_{011}\right) / k T}$, where $T_{v}$ is the vibrational transition probability and $\left(E_{v}-E_{011}\right)$ is the energy difference between the $J=0$ level of the upper state in the transition and $J=0$ of (011). The vibrational energy levels involved, with a few exceptions, have been observed in absorption, and the corresponding values of $\nu_{0}=E_{v}^{\prime}-E_{v}^{\prime \prime}$ are given to $0.1 \mathrm{~cm}^{-1}$; unobserved levels are calculable from the vibrational energy formula [3], and should be accurate to a few wave numbers. $T_{v}$ and $I$ are expressed relative to 1.00 for $011-000$; the former is proportional to $v_{2}^{\prime} v_{3}^{\prime}$, a result that is theoretically exact to first approximation, assuming that the combination transition (which is foridden if the dipole moment may be expanded in purely linear terms in harmonic normal coordinates) is due to cubic and quadratic anharmonic terms in the molecular potential function and to quadratic terms in the dipole expansion [11].

Each band in table 3 is designated in brief by a letter symbol. The calculated intensities are the products of rotational intensity factors like those in table 2 and the vibrational factors of table 3 . A few of the higher bands in table 3 involve DarlingDennison [12] resonance pairs $\left(v_{1+2} v_{2} v_{3}\right.$ with $\left.v_{1} v_{2} v_{3+2}\right)$. For these the intensities are taken proportional to the fraction of $2 \nu_{3}$ in the perturbed wave function, a rather questionable assumption because the intensity relation in cases of resonance are complicated by phase factors [13]. Table 3 contains 11 bands with $I>0.12$. Table 1 shows that numerous assignments 
have been made to the seven of these for which both upper and lower energy states had been observed in absorption; that the strongest lines of the $P$ and $R$ series have been identified for two bands, 022-011(j) and $032-021(\mathrm{k})$, of which the lower state energies had previously been known; and that a few assignments have tentatively been made for the strongest remaining band, $051-040(\mathrm{~h})$, of which both the upper and lower state are newly observed. No assignments have been made for band $i$.

TABLE 3.-Vibrational band origins and relative intensities at $2,877^{\circ} \mathrm{K}$

\begin{tabular}{|c|c|c|c|c|c|c|c|c|c|c|}
\hline $\begin{array}{l}\text { Band } \\
\text { desig- } \\
\text { nation }\end{array}$ & $v_{1}^{\prime}$ & $v_{2}^{\prime}$ & $v_{3}^{\prime}$ & $v_{1}^{\prime \prime}$ & $v_{2}^{\prime \prime}$ & $v_{3}^{\prime \prime}$ & $\nu_{0}$ & $T_{\mathrm{v}}$ & $I_{2,877^{\circ}}$ & $\begin{array}{l}\text { Num- } \\
\text { ber of } \\
\text { identi- } \\
\text { fied } \\
\text { lines }\end{array}$ \\
\hline a.... & 0 & 1 & 1 & 0 & 0 & 0 & $\begin{array}{c}\mathrm{cm}^{-1} \\
5331.2\end{array}$ & 1. 00 & 1.00 & 424 \\
\hline b $\ldots$ & 0 & 2 & 1 & 0 & 1 & 0 & 5277.0 & 2. 00 & 0.90 & 234 \\
\hline $\mathbf{c}_{\ldots} \ldots$ & 0 & 3 & 1 & 0 & 2 & 0 & 5221.8 & 3. 00 & .62 & 113 \\
\hline$d_{\ldots} \ldots$ & 0 & 4 & 1 & 0 & 3 & 0 & 5166.9 & 4. 00 & .39 & 64 \\
\hline h.... & 0 & 5 & 1 & 0 & 4 & 0 & 5112 & 5. 00 & .23 & 5 \\
\hline i.... & 0 & 6 & 1 & 0 & 5 & 0 & 5067 & 6. 00 & .12 & -... \\
\hline$e_{\ldots} \ldots$ & 0 & 1 & 2 & 0 & 0 & 1 & 5244.3 & 1.78 & .28 & 96 \\
\hline$j_{\ldots}$ & 0 & 2 & 2 & 0 & 1 & 1 & 5192 & 3. 55 & .25 & 20 \\
\hline$k_{\ldots} \ldots$ & 0 & 3 & 2 & 0 & 2 & 1 & 5139 & 5. 31 & .16 & 14 \\
\hline$f_{\ldots} \ldots$ & 1 & 1 & 1 & 1 & 0 & 0 & 5149.9 & 1.00 & .16 & 39 \\
\hline g.... & 1 & 2 & 1 & 1 & 1 & 0 & 5093.7 & 2. 00 & .15 & 32 \\
\hline
\end{tabular}

The identification of a line is considered sufficiently convincing for inclusion in table 1 when both the frequency and intensity checks are satisfactory. For a satisfactory frequency check, the line position must be within $0.4 \mathrm{~cm}^{-1}$ of the calculated position. This calculated position is derived by taking the difference between the two energy states involved in the transition. The quantum numbers of these states are given in the central column of table 1 . The corresponding energies are listed in table 4 for the two upper states of greatest importance in the $1.9-\mu$ region, namely, 011 and 021 . The lower-state energies of $000,010,020,100$, and 001 have been given in recent publications $[8,14,15]$. Other upper- and lower-state energy levels, particularly for the low $J$ values, were derived from atmosphericabsorption data and will be published elsewhere. New levels of the upper states 012, 022, and 032 derived from the present data are given in table 5 . Agreement of an observed and calculated frequency implies that the frequency difference between two or more emission lines is in accord with the corresponding difference in two or more (often as many as 50) absorption lines. It does not mean that the energy levels can be calculated to an accuracy of $0.4 \mathrm{~cm}^{-1}$ from molecular constants because the centrifugal-stretching and perturbation effects are so large as to make these calculations prohibitively difficult. However, the energy levels do agree roughly with what is to be expected, as may be seen from a comparison in table 6 of the rotational energy levels for $J=12$ of the 000 and 011 states, calculated on the rigid rotator approximation. For 000 the constants used were $A=27.877, B=14.512, C=9.285$ $\mathrm{cm}^{-1}$; for $011, A=29.54, B=14.59, C=9.014$. The calculated energies are compared with the observed rotational energies $E^{\prime}-E_{J=0}$; the differences $\Delta$ are chiefly due to centrifugal stretchings. They are consistently greater by about 40 percent for 011 , but follow a very similar pattern for the two vibrational states. The only rotational level of 011 that shows an anomalous $\Delta$ is $12_{-4}$. The large discrepancy here can readily be attributed to perturbation by $12_{-5}$ of 110 , whose unperturbed energy should lie within $10 \mathrm{~cm}^{-1}$ of the unperturbed energy of $12_{-4}$ of 011 , because the calculated rotational-energy difference is $+94.3 \mathrm{~cm}^{-1}$ and the vibrational difference -96.2 $\mathrm{cm}^{-1}$. Similar calculations from inertial constants have been made for other $J$ values, and likewise confirm the assignments.

TABLE 4. Energy levels $\left(\mathrm{cm}^{-1}\right)$ of 011 and 021 vibration states

\begin{tabular}{|c|c|c|c|c|c|}
\hline \multirow{2}{*}{$J_{\tau}$} & \multicolumn{2}{|c|}{$v_{1} v_{2} v_{3}$} & \multirow{2}{*}{$J_{\tau}$} & \multicolumn{2}{|c|}{$v_{1} v_{2} v_{3}$} \\
\hline & 011 & 021 & & 011 & 021 \\
\hline $0_{0}$ & 5331.19 & 6871.65 & $6_{3}$ & 6251.73 & \\
\hline & & & $6_{4}$ & 6251.77 & 7869.16 \\
\hline $1_{-1}$ & 5354.78 & 6895.06 & 65,6 & 6420.17 & 8063.49 \\
\hline $1_{0}$ & 5369.76 & 6913.55 & & & \\
\hline $1_{1}$ & 5375.41 & 6919. 44 & $\begin{array}{l}7-7 \\
7-6\end{array}$ & $\begin{array}{l}5907.70 \\
5907.91\end{array}$ & $\begin{array}{l}7448.47 \\
7449.07\end{array}$ \\
\hline $2-2$ & 5400.68 & 6941.04 & $7-5$ & 6035.08 & 7587.68 \\
\hline $2-1$ & 5411.42 & 6954.95 & $7-4$ & 6041.11 & 7598.33 \\
\hline $2_{0}$ & 5428.16 & 6972.75 & $7-3$ & 6118.75 & 7676.30 \\
\hline $2_{1}$ & 5472. 29 & 7027. 31 & $7-2$ & 6156.56 & 7730.09 \\
\hline $2_{2}$ & 5473.62 & 7028.42 & $7-1$ & 6179.78 & 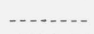 \\
\hline $3-3$ & 5466.58 & 7007.26 & 70 & 6277.87 & 7871.75 \\
\hline $3-2$ & 5473.13 & 7016.62 & $7_{1}$ & 6281.20 & 7874.5 \\
\hline $3-1$ & 5506.32 & 7051.44 & $7_{2}$ & 6421.44 & 8039.88 \\
\hline $3_{0}$ & 5544.22 & 7098.15 & 73 & 6421.58 & \\
\hline $3_{1}$ & 5549.67 & 7105.52 & $7_{4,5}$ & $\begin{array}{r}6590.10 \\
6780.48\end{array}$ & 8233.79 \\
\hline $3_{2}$ & 5629.97 & 7201.64 & 76,7 & 6780.48 & 8450.85 \\
\hline $3_{3}$ & 5630.13 & 7201.81 & $8-8$ & 6061.98 & 7602.12 \\
\hline $4-4$ & 5550.65 & 7091.94 & $8-7$ & 6061.98 & 7602.39 \\
\hline $4-3$ & 5552.98 & 7096.65 & $8-6$ & 6212.07 & 7767.32 \\
\hline $4-2$ & 5608.29 & 7154.40 & $8-5$ & 6215.15 & 7773.22 \\
\hline $4-1$ & 5639.69 & 7191. 22 & $8-4$ & 6318.73 & 7879.29 \\
\hline $4_{0}$ & 5652.98 & 7205.25 & $8-3$ & 6344.56 & \\
\hline $4_{1}$ & 5726.27 & 7298.27 & $8-2$ & 6394. 27 & 7958.54 \\
\hline $4_{2}$ & 5727.51 & 7299.32 & $8-1$ & 6471.22 & \\
\hline $4_{3}$ & 5842.02 & 7435. 28 & $8_{0}$ & 6479.95 & 8073. 28 \\
\hline $4_{4}$ & 5842.02 & 7435.28 & $8_{1}$ & 6615.32 & \\
\hline & & & $8_{2}$ & 6616.07 & 8234.01 \\
\hline $5-5$ & 5652.10 & 7193.45 & $8_{3,4}$ & 6784.02 & 8428.09 \\
\hline $5-4$ & 5653.55 & 7196.08 & 85,6 & 6975.17 & 8646.42 \\
\hline 5-3 & 5731.93 & 7279.65 & $8_{7,8}$ & 7184.74 & 8882.29 \\
\hline $5-2$ & 5749.70 & 7306.40 & & & \\
\hline $5-1$ & 5783.36 & 7338.92 & $9-9$ & 6234.07 & 7772.95 \\
\hline $5_{0}$ & 5846.47 & 7418.89 & 9-8 & 6234.07 & 7773.05 \\
\hline $5_{1}$ & 5851.26 & 7422.95 & $9-7$ & 6406. 20 & - \\
\hline $5_{2}$ & 5963.03 & 7556.36 & $9-6$ & 6407.60 & 7966.97 \\
\hline $5_{3}$ & 5963.16 & 7556.46 & $9-5$ & 6537.13 & - \\
\hline 54,5 & 6106.26 & 7723.57 & $9-4$ & 6553.37 & 8128.39 \\
\hline & & 731248 & 9-3 & 6624.67 & 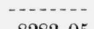 \\
\hline $\begin{array}{l}0-6 \\
6-5\end{array}$ & $\begin{array}{l}\text { 571.09 } \\
5771.68\end{array}$ & $\begin{array}{l}7312.48 \\
7313.55\end{array}$ & $9_{-2}$ & $\begin{array}{r}6687.75 \\
6706\end{array}$ & 8282.00 \\
\hline $6-4$ & 5874.72 & 7424.78 & $\begin{array}{l}-1-1 \\
9_{0}\end{array}$ & $\begin{array}{l}6706.19 \\
6833.27\end{array}$ & 8452.35 \\
\hline $6-3$ & 5885.70 & 7442.35 & $9_{1}$ & 6835.48 & - \\
\hline $6-2$ & 5939. 32 & 7495.02 & $9_{2}$ & 7001.8 & 8646.30 \\
\hline $6-1$ & 5990.15 & 7563.19 & $9_{3}$ & 7002.0 & --o-s \\
\hline 60 & 6002.31 & 7573.75 & $9_{4.5}$ & 7193.3 & $\ldots$ \\
\hline $6_{1}$ & 6108. 51 & 7701.80 & $9_{6,7}$ & 7404.2 & 9103.05 \\
\hline $6_{2}$ & 6109.33 & 7702.56 & 98,9 & 7630.4 & - \\
\hline
\end{tabular}


TABLE 4. Energy levels $\left(\mathrm{cm}^{-1}\right)$ of 011 and 021 vibration states - Continued

\begin{tabular}{|c|c|c|c|c|c|}
\hline \multirow{2}{*}{$J_{\tau}$} & \multicolumn{2}{|c|}{$v_{1} v_{2} v_{3}$} & \multirow{2}{*}{$J_{\tau}$} & \multicolumn{2}{|c|}{$v_{1} v_{2} v_{3}$} \\
\hline & 011 & 021 & & 011 & 021 \\
\hline $10_{-10,-9}$ & 6423.82 & 7961.73 & $12_{9,10}$ & 8940.5 & \\
\hline $10_{-8}$ & 6617.35 & 8176.59 & $12_{11,12}$ & 9208.7 & \\
\hline $10_{-7}$ & 6618.11 & 8178.21 & & & \\
\hline $10_{-6}$ & 6772.07 & 8341.5 & $13-13,-12$ & 7099.27 & 8632.4 \\
\hline $10_{-5}$ & 6781.45 & 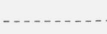 & $13-11,-10$ & 7355.4 & 8918.5 \\
\hline $10_{-4}$ & 6878.66 & 8453.04 & $13-9$ & 7575.27 & 9159.3 \\
\hline $10_{-3}$ & 6926.26 & - n & $13_{-8}$ & 7575.94 & \\
\hline $10_{-2}$ & 6959.66 & 8540.67 & $13-7$ & 7753.61 & \\
\hline $10_{-1}$ & 7075.14 & - & $13_{-6}$ & 7766.40 & \\
\hline $10_{0}$ & 7080.58 & 8698.11 & $13-5$ & 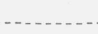 & \\
\hline $10_{1}$ & 7243.72 & - & $13-4$ & 7942.36 & \\
\hline $10_{2}$ & 7244.36 & & $13_{-3}$ & - & \\
\hline $10_{3,4}$ & 7435.4 & . & $13_{-2}$ & 8105.32 & \\
\hline $10_{5,6}$ & 7647.3 & 9347.6 & $13-1$ & . & \\
\hline $10_{7,8}$ & 7874.7 & - & $13_{0,1}$ & 8302. 26 & \\
\hline 109,10 & 8115.1 & - & $13_{2,3}$ & (- & \\
\hline & & & $13_{4,5}$ & 8746.0 & \\
\hline $\begin{array}{l}11_{-11,-10} \\
11_{-g}\end{array}$ & $\begin{array}{l}6631.42 \\
6846.07\end{array}$ & 8167.78 & $13_{6,7}$ & 8992 & -- \\
\hline $\begin{array}{l}11-8 \\
11_{-8}\end{array}$ & $\begin{array}{l}6846.07 \\
6846.42\end{array}$ & 8407.21 & $14-14,-13$ & 7358,68 & 8889.6 \\
\hline $11-7$ & 7023.36 & 20 & $14-12,-11$ & 7637.0 & 9198.9 \\
\hline $11_{-6}$ & 7028.50 & 8607.68 & $14-10$ & 7876.21 & (1) \\
\hline $11_{-5}$ & 7152.76 & - & $14-9$ & 7876.46 &.- \\
\hline $11-4$ & 7185.97 & 8782.75 & $14-8$ & 8078.87 & \\
\hline $11_{-3}$ & 7237.48 & - & $14-7$ & 8085.12 & \\
\hline $11_{-2}$ & 7340.12 & 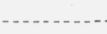 & & & \\
\hline $11_{-1}$ & 7352.05 & 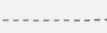 & $15-15,-14$ & 7636.8 & 9165.2 \\
\hline $11_{0}$ & 7509.0 & - & $15_{-13,-12}$ & 7935.5 & . \\
\hline $11_{1}$ & 7510.8 & - & $15-11,-10$ & 8195.6 & \\
\hline $11_{2,3}$ & 7700.8 & - & $15-9$ & . & \\
\hline $11_{4,5}$ & 7913.2 & & $15-8$ & 8425.2 & \\
\hline $11_{6,7}$ & 8142.6 & - & & & \\
\hline $11_{8,9}$ & 8385.0 & 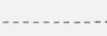 & $16-16,-15$ & 7931.9 & 9457.8 \\
\hline $11_{10,11}$ & 8638.4 & & $16-14,-13$ & 8250.4 & \\
\hline & & & $16-12,-11$ & 8532.9 & \\
\hline $12-12,-11$ & 6856.48 & 8391.4 & & & \\
\hline $12-10,-9$ & 7092.4 & 8654.07 & $17_{-17,-16}$ & 8244.1 & 9767.8 \\
\hline $12-8$ & 7290.7 & 8869.4 & $17-15,-14$ & 8583.7 & \\
\hline $12-7$ & 7293.4 & - n & $17_{-13,-12}$ & 8885.5 & \\
\hline $12_{-6}$ & 7444.05 & 9024.1 & & & \\
\hline $12_{-5}$ & 7466.10 & & $18-18,-17$ & 8573.4 & \\
\hline $12-4$ & 7554.46 & & $18-16,-15$ & 8933.7 & \\
\hline $12-3$ & 7627.38 & & $18_{-14,-13}$ & 9255.2 & \\
\hline $12_{-2}$ & 7650.73 & & & & \\
\hline $12_{-1}$ & 7795.95 & 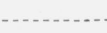 & $19_{-19,-18}$ & 8920.1 & \\
\hline $12_{0}$ & 7800.0 & & $19-17,-16$ & 9305.6 & \\
\hline $12_{1,2}$ & 7990.7 & & & & \\
\hline $12_{3,4}$ & 8202. 3 & - & $20-20,-19$ & 9283.5 & \\
\hline $12_{5,6}$ & 8432.6 & & & & \\
\hline $12_{7,8}$ & 8677.5 & - & $21-21,-20$ & 9664.5 & - \\
\hline
\end{tabular}

Another way in which the reasonableness of the observed energy levels may be seen (in addition to the good agreement of the combination differences and calculations of the type first mentioned) is in the arrangement of the energy levels, or of the observed lines, in series that show regular trends with $J$ and $(J+\tau)$. Two such arrays will be demonstrated; others can readily be assembled from the data of table 1 . In table 7 the lines of the $R_{01}$ branch, for $J \geqq 8$, are tabulated. Regularities may be noted for all the values of $(J+\tau)$, and the way in which the various $(J+\tau)$ series diverge and converge is characteristic. There is an obvious perturbation of
TABLe 5. Energy levels $\left(\mathrm{cm}^{-1}\right)$ of 012, 022, and 032 vibration states

\begin{tabular}{|c|c|c|c|c|c|c|c|}
\hline \multirow{2}{*}{$J_{\tau}$} & \multicolumn{3}{|c|}{$v_{1} v_{2} v_{3}$} & \multirow{2}{*}{$J_{\tau}$} & \multicolumn{3}{|c|}{$v_{1} v_{2} v_{3}$} \\
\hline & 012 & 022 & 032 & & 012 & 022 & 032 \\
\hline $0_{0}$ & 9000.10 & & & $7_{-4}$ & & - & 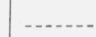 \\
\hline & & & & $7_{-3}$ & 9772.48 & -.... & - n. \\
\hline $1_{-1}$ & 9023.51 & - & - & $7-2$ & & - & - \\
\hline $1_{0}$ & 9037. 20 & & & $7_{-1}$ & 9833.65 & - & - \\
\hline $1_{1}$ & 9042.79 & & ....... & $7_{0}$ & 9924. 9 & -....... & -...... \\
\hline & & & & $7_{1}$ & 9928.99 & - & -....... \\
\hline $2-2$ & 9068.74 & - & - & $7_{2}$ & 10060.76 & - & - \\
\hline $2-1$ & 9078. 29 & & - & $7_{3}$ & 10061.15 & -....... & -....... \\
\hline 20 & 9095.16 & & - & $7_{4,5}$ & 10211. 83 & - & -...- \\
\hline $2_{1}$ & 9135.82 & -....... & -...... & $7_{6,7}$ & 10395.5 & ......... & - \\
\hline $2_{2}$ & 9137.21 & -....... & & $8-8,-7$ & 9718.90 & 11235.2 & 12718.8 \\
\hline $3-3$ & 9133.58 & & - & $8-6$ & -...-. & $\ldots$ & ...... \\
\hline $3-2$ & 9138.98 & & - & $8-5$ & 9864.09 & - & - \\
\hline $3-1$ & 9172.47 & -...... & -...... & $8-4$ & & -n..... & - \\
\hline $3_{0}$ & 9205. 99 & -...... & -....... & $8-3$ & 9995.6 & -....... & ........ \\
\hline $3_{1}$ & 9212.47 & ....... & (....... & $8-2$ & ....... & -..... & -....- \\
\hline $3_{2}$ & 9287. 18 & -....... & ........ & $8-1$ & 10116.86 & -.....- & (n) \\
\hline $3_{3}$ & 9287.42 & -... & -....... & $\begin{array}{l}8_{0} \\
8_{1}\end{array}$ & $\begin{array}{r}-\cdots 254.39 \\
1025\end{array}$ & - & - \\
\hline $4-4$ & 9216.10 & & & $8_{2}$ & - & -...... & ........ \\
\hline $4-3$ & 9218.82 & - & - & 83,4 & -...... & - & - \\
\hline $4-2$ & 9273.19 & -...... & -....... & 85,6 & 10588.4 & -....... & - \\
\hline $4-1$ & 9298.19 & -....... & - n- & & & & 12887.1 \\
\hline $4_{0}$ & 9315.1 & ........ & ....... & $9-9,-8$ & 9887.9 & 11403.9 & 12887.1 \\
\hline $4_{1}$ & 9383.09 & - & -...... & $9-7$ & 10056.69 & -...... & -..... \\
\hline $4_{2}$ & 9384.57 & - & - & $9-6$ & -....... & -........ & -....... \\
\hline $4_{3,4}$ & 9490.92 & $\cdots$ & & $\begin{array}{l}9-5 \\
9-4\end{array}$ & -........ & - & - \\
\hline $5-5$ & 9316.14 & - & - & $9-3$ & - & -....... & -..... \\
\hline $5-4$ & 9316. 97 & - & - & $9-2$ & - & - & -...... \\
\hline $5-3$ & 9394.95 & - & & $9-1$ & - & -n. & - \\
\hline $5-2$ & 9411.60 & ...... & & $9_{0}$ & -...... & -....... & -...... \\
\hline $5_{-1}$ & 9444.69 & -...... & & $9_{1}$ & - & - & - \\
\hline $5_{0}$ & 9502.64 & -...... & $\cdots$ & $9_{2,3}$ & & -...- & -...... \\
\hline $5_{1}$ & 9508.18 & -...-. & -...... & $9_{4,5}$ & 10805.5 & ........ & - \\
\hline $5_{2}$ & 9611.48 & ....... & ....... & $9_{6,7}$ & 11004.1 & . & - \\
\hline $5_{3}$ & $\begin{array}{l}9611.79 \\
9745.59\end{array}$ & . & & $10-10,-9$ & 10074.61 & 11590.1 & 13073.0 \\
\hline 54,5 & 9745.59 & & & $10-8$ & 10264.9 & & -.... \\
\hline $6-6-$ & 9432.52 & -...... & & & & & \\
\hline $6-5$ & 9433.51 & - & $\cdots$ & $11_{-11,-10}$ & 10279.1 & 11793.1 & 13276.0 \\
\hline $6-4$ & 9533.18 & -....... & - & $11-9,-8$ & 10490.7 & -....... & -...... \\
\hline $6-3$ & 9545.32 & -...... & - & & & & \\
\hline $6-2$ & 9598.2 & -...-. &..- & $12-12,-11$ & 10501.2 & 12013. 5 & 13495.9 \\
\hline $6-1$ & 9645.23 & - & - & $12-10,-9$ & 10732.9 & 12271.0 & - - \\
\hline $6_{0}$ & 9657.66 & - & 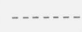 & & & & \\
\hline $6_{1}$ & 9756. 20 & ...... & & $13-13,-12$ & 10740.9 & 12250.8 & 13731.1 \\
\hline $6_{2}$ & 9757.53 & -...... & -.... & $13-11,-10$ & 10992.2 & 12528.2 & ......... \\
\hline 63,4 & 9891.22 & - & $-\cdot$ & & & 12504.6 & 13984.2 \\
\hline $6_{5,6}$ & 10047. 54 & -...... & & $14-14,-13$ & 10996.3 & & \\
\hline $7-7$ & 9566. 91 & -..-... & & $15_{-15,-14}$ & 11268.8 & 12774.6 & ......... \\
\hline $\begin{array}{l}7_{-6} \\
7_{-5}\end{array}$ & $-\ldots 602 \quad 27$ & - & & $16-16,-15$ & 11558.2 & & \\
\hline & 9092.28 & & & & & & \\
\hline
\end{tabular}

the $(J+\tau)=8$ series at $J=12$, as mentioned above; similar perturbations of $(J+\tau)=6$ and $(J+\tau)=4$ occur at lower $J$ values. The highest $J$ entries in table 7 are rather uncertain, inasmuch as they cannot be confirmed by combination differences; on the basis of the series regularities and intensities they appear plausible however. Note that at frequencies greater than $5,560 \mathrm{~cm}^{-1}$ practically all of the identified lines belong to this branch, and that the array 
TABle 6. Rotational energies for $J=12$

\begin{tabular}{|c|c|c|c|c|c|c|}
\hline \multirow{2}{*}{$\tau$} & \multicolumn{3}{|c|}{011} & \multicolumn{3}{|c|}{000} \\
\hline & $\begin{array}{l}\text { Calcu- } \\
\text { lated }\end{array}$ & $\begin{array}{c}\text { Ob- } \\
\text { served }\end{array}$ & $\Delta$ & $\begin{array}{l}\text { Calcu- } \\
\text { lated }\end{array}$ & $\begin{array}{c}\text { Ob- } \\
\text { served }\end{array}$ & $\Delta$ \\
\hline & $\mathrm{cm}^{-1}$ & $\mathrm{~cm}^{-1}$ & $\mathrm{~cm}^{-1}$ & $\mathrm{~cm}^{-1}$ & $\mathrm{~cm}^{-1}$ & $\mathrm{~cm}^{-1}$ \\
\hline$-12,-11$ & 1533.26 & 1525. 29 & 7.97 & 1565.62 & 1558.07 & 7.55 \\
\hline-10 & 1773.43 & 1761.20 & 12. 23 & 1787.22 & 1774.75 & 12.47 \\
\hline-9 & 1773.53 & 1761.20 & 12.33 & 1787.29 & 1774.88 & 12.41 \\
\hline-8 & 1983.12 & 1959.50 & 23.62 & 1981. 36 & 1960. 38 & 20.98 \\
\hline-7 & 1985.12 & 1962. 20 & 22.92 & 1982. 24 & 1962.60 & 19.64 \\
\hline-6 & 2150.24 & 2112.86 & 37.38 & 2138.02 & 2106.70 & 31.32 \\
\hline-5 & 2169.78 & 2134.91 & 34.87 & 2153.31 & 2124.84 & 28.47 \\
\hline-4 & 2264.04 & 2223.27 & 40.77 & 2245. 29 & 2205.95 & 39.34 \\
\hline-3 & 2342.16 & 2296. 19 & 45.97 & 2310.81 & 2275.65 & 35.16 \\
\hline-2 & 2371.52 & 2319.54 & 51.98 & 2341.38 & 2300.94 & 40.44 \\
\hline-1 & 2528.39 & 2464.76 & 63.63 & 2478.72 & 2434.14 & 44.58 \\
\hline 0 & 2532.38 & 2468.80 & 63.58 & 2483.18 & 2437.84 & 45.34 \\
\hline 1 & 2747.47 & 2659.50 & 87.97 & 2675.37 & 2613.26 & 62.11 \\
\hline 2 & 2747.74 & 2659.50 & 88.24 & 2675.70 & 2613.49 & 62.21 \\
\hline 3,4 & 3004.33 & 2871.10 & 133. 23 & 2906.07 & 2813.94 & 92.13 \\
\hline 5,6 & 3298.49 & 3101.40 & 197.09 & 3170.48 & 3033.17 & 137.31 \\
\hline 7,8 & 3629.13 & 3346.30 & 282.83 & 3467.84 & 3267.20 & 200.64 \\
\hline 9,10 & 3995. 78 & 3609.30 & 386.48 & 3797.67 & 3512.80 & 284.87 \\
\hline 11,12 & 4398.15 & 3877.50 & 520.65 & 4159. 71 & 3767.10 & 392.61 \\
\hline
\end{tabular}

of table 7 includes most of the strong lines in that region.

Table 8 shows the series regularities of the strongest $P_{\overline{01}}$ branches, those with $J+\tau=0$, for all the bands; it will be noted that there are also regularities in the vibration sequences. In addition to the line frequencies, the line intensities are tabulated; when overlapping occurs, the intensities are given in parentheses. The theoretical rotational and vibrational intensity factors are also given.

Table 8 also demonstrates the second criterion, by which it is believed that the correct assignment has been made, namely, the agreement between the observed and calculated intensities. Both for the lines in table 8 and throughout the assignments there is gratifying parallelism between those quantities. Better agreement could hardly be expected, since it must be realized that the observed intensities are often irregualrly disturbed by weak neighboring lines (not to mention the large disturbances by atmospheric absorption of many lines, including all those of band a, between 5,100 and $5,600 \mathrm{~cm}^{-1}$ ), and that the analysis is incomplete, so that unidentified transitions of higher $J$ may be making additional contributions. The necessary condition for a satisfactory analysis, that no lines of high and medium intensity are predicted where there is no emission, has been met.

The agreement between the observed intensities of unblended lines and those calculated for $2,877^{\circ} \mathrm{K}$ shows that there is a possibility of using the $\mathrm{H}_{2} \mathrm{O}$ emission for temperature determination. This cannot be done with complete confidence, however, until an even more complete analysis, or better resolution, has been achieved. On the basis of the present results it would appear that in the flames studied there is equilibrium within both the rotational and vibrational degrees of freedom, and that the temperature is within perhaps $500^{\circ}$ of $2,877^{\circ} \mathrm{K}$. While it is gratifying that an assignment can be given to nearly 90 percent of the lines observed, and that this accounts for all the predicted lines of intensity greater than 10 and about 75 percent of the total predicted intensity, there are no clear-cut criteria, as there are in the spectra of diatomic molecules, for determining whether a weak unassigned line may not be contributing to the observed intensity. Hence, although it is tempting to use the observed relative intensities of two lines that lie close in frequency but come from widely different energy levels, such as $5,600.65 \mathrm{~cm}^{-1},\left(E^{\prime}=8,920\right)$ and $5,602.55 \mathrm{~cm}^{-1}\left(E^{\prime}=\right.$ $7,193)$ as a "thermometric pair", it may lead to error unless still higher resolution reveals the lines to be truly single.

The analysis also shows that there is no simple correlation between the frequency and the upperstate energy. In general, it is the case that the emission comes from higher and higher levels as one goes toward the wings of the band, but there are frequent exceptions inasmuch as the various bands, and the various sub-branches of a given band, overlap in a complicated manner. Hence it is questionable whether measurements with low-resolution spectrometers, comparing the relative intensity and emissivity in frequency intervals 10 to $20 \mathrm{~cm}^{-1}$ wide, could yield temperature determinations of high accuracy. There is no doubt however that measurements of this kind would be useful in a rough way, particularly if the present results are used to choose frequency ranges where the radiation comes principally from levels of nearly the same $E^{\prime}$.

It was stated earlier that the empirical evidence indicated that the maximum emissivity did not exceed 0.2 to 0.4 at the cores of the strongest lines. This is a condition that is necessary if self-absorption effects are not to vitiate intensity measurements and temperature determinations $[16,17]$. The emissivity of the strongest line, at $4,999.9 \mathrm{~cm}^{-1}$, may be calculated approximately from the following data. The relative line intensity (sum of the three components listed in table 1) is 52. The total integrated intensity of the band, as determined from absorption measurements, is equivalent to $20 \mathrm{~cm}^{-2} \mathrm{~atm}^{-1}$ (atmosphere here refers to standard temperature and pressure). The fraction of this in the $5,000 \mathrm{~cm}^{-1}$ line is $20 \times$ $52 / Q_{r} Q_{v}$, where the $Q$ values are the rotational and vibrational partition functions, respectively 5,550 and 2.62 at $2,877^{\circ} \mathrm{K}$. Hence the integrated absorption coefficient of the line is $0.072 \mathrm{~cm}^{-2} \mathrm{~atm}^{-1}$. If the path length is $2 \mathrm{~cm}$ and the $\mathrm{H}_{2} \mathrm{O}$ content of the outer-cone gas 80 percent, there are $0.80 \times 273 / 2877=0.152$ $\mathrm{cm}$ atm of $\mathrm{H}_{2} \mathrm{O}$ in the line of sight. Hence the total line strength, $S$, is $0.072 \times 0.152=1.1 \times 10^{-3} \mathrm{~cm}^{-1}$. The line shape will probably be Lorentzian, with a half-width $\gamma_{L}$ of the order of $0.05 \mathrm{~cm}^{-1}$. (The half-width of pure $\mathrm{H}_{2} \mathrm{O}$ vapor at $100^{\circ} \mathrm{C}$ and $1 \mathrm{~atm}$ is about $0.4 \mathrm{~cm}^{-1}$; its variation with temperature and pressure is uncertain, but the above estimate is of the correct order of magnitude, and is somewhat 
TABLE 7. Series regularities in the $R_{0,1}$ branch of 011-000

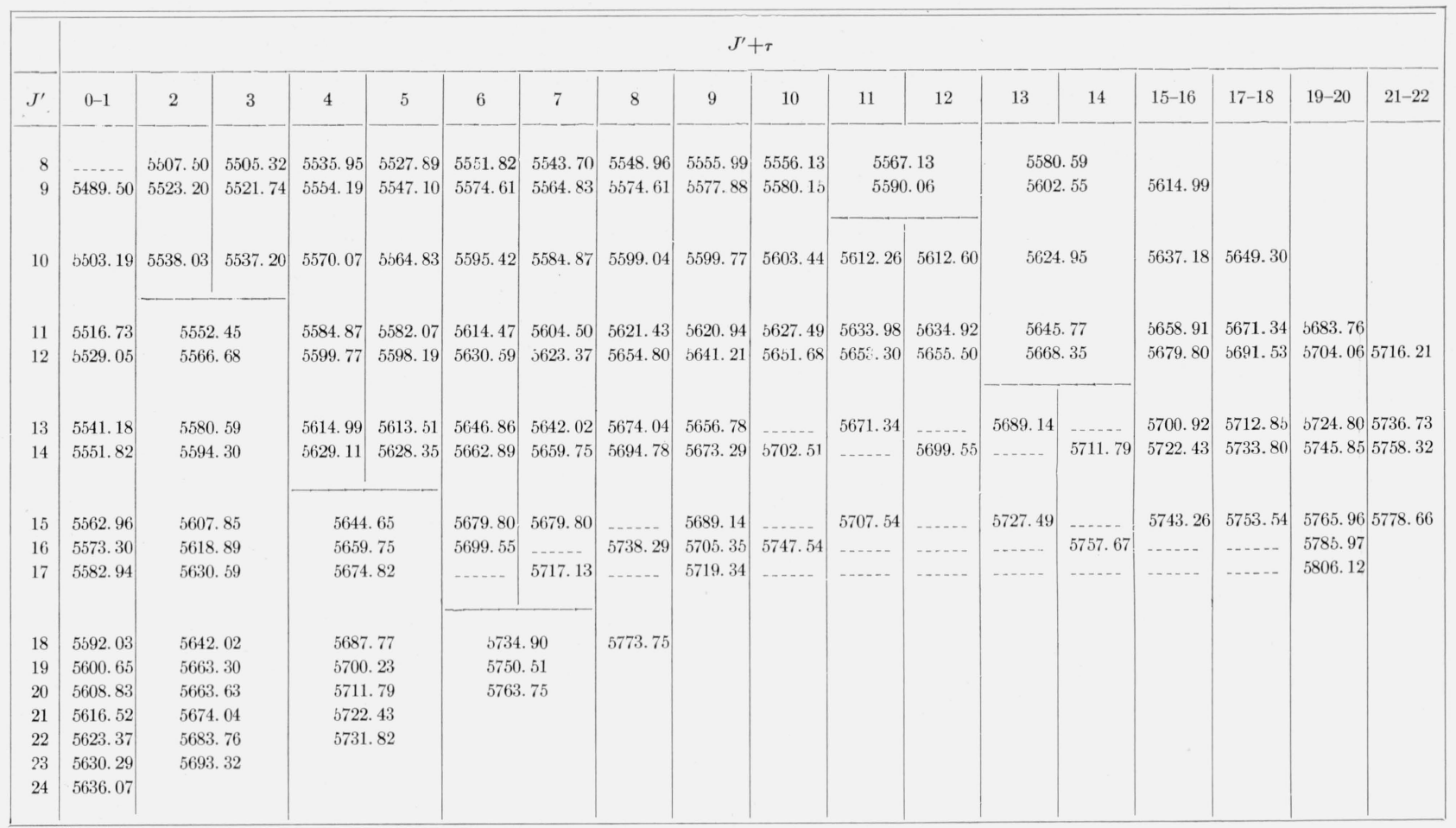

TABLE 8. $J+\tau=0$ series in the $P_{01}$ branches of 10 bands in the $011-000$ sequence

\begin{tabular}{|c|c|c|c|c|c|c|c|c|c|c|c|c|c|c|c|c|c|c|c|c|c|}
\hline \multirow{3}{*}{$J^{\prime}$} & \multirow{3}{*}{$\begin{array}{c}\text { Band } \\
v^{\prime} \\
v^{\prime \prime} \ldots \\
\text { vif a } \\
\text { rif b }\end{array}$} & \multicolumn{2}{|l|}{$\begin{array}{c}\mathrm{a} \\
011 \\
000\end{array}$} & \multicolumn{2}{|l|}{$\begin{array}{c}\mathrm{b} \\
021 \\
010\end{array}$} & \multicolumn{2}{|l|}{$\begin{array}{c}\mathrm{c} \\
031 \\
020\end{array}$} & \multicolumn{2}{|c|}{$\begin{array}{c}\mathrm{d} \\
041 \\
030\end{array}$} & \multicolumn{2}{|l|}{$\begin{array}{c}\mathrm{h} \\
051 \\
040\end{array}$} & \multicolumn{2}{|l|}{$\begin{array}{c}\mathrm{e} \\
012 \\
001\end{array}$} & \multicolumn{2}{|l|}{$\begin{array}{c}\mathrm{j} \\
022 \\
011\end{array}$} & \multicolumn{2}{|l|}{$\begin{array}{c}\mathrm{k} \\
032 \\
021\end{array}$} & \multicolumn{2}{|l|}{$\begin{array}{c}\mathrm{f} \\
111 \\
100\end{array}$} & \multicolumn{2}{|l|}{$\begin{array}{r}\mathrm{g} \\
121 \\
110\end{array}$} \\
\hline & & \multicolumn{2}{|l|}{100} & \multicolumn{2}{|l|}{90} & \multicolumn{2}{|l|}{62} & \multicolumn{2}{|l|}{39} & \multicolumn{2}{|l|}{23} & \multicolumn{2}{|l|}{28} & \multicolumn{2}{|l|}{25} & \multicolumn{2}{|l|}{16} & \multicolumn{2}{|l|}{16} & \multicolumn{2}{|l|}{15} \\
\hline & & $\nu$ & $I$ & $\nu$ & $I$ & $\nu$ & $I$ & $\nu$ & $I$ & $\nu$ & $I$ & $\nu$ & $I$ & $\nu$ & $I$ & $\nu$ & $I$ & $\nu$ & $I$ & $\nu$ & $I$ \\
\hline 7 & 23 & 5163.86 & 15 & 5110.84 & 41 & 5059.45 & 40 & 5005.18 & 35 & - . & -- & 5078.75 & (26) & & & & & & & & \\
\hline 8 & 24 & 41.95 & 30 & 5089.95 & 45 & 37.91 & 32 & 4985. 36 & 25 & - & -- & 57.35 & 18 & 5001.55 & 17 & 4945. 71 & 20 & 4963.83 & 30 & 4910.80 & (35) \\
\hline 9 & 25 & 19. 63 & 48 & 67.91 & 45 & 16.86 & 35 & 65. 39 & 37 & 4915.83 & 22 & 34.99 & 16 & 4980.12 & 14 & 25.35 & 19 & 42.49 & 25 & 4890.00 & 55 \\
\hline 10 & 25 & 5096.57 & 45 & 45.79 & 45 & 4995. 23 & 25 & 44. 76 & 30 & 4896.02 & 11 & 12.39 & (21) & 58.84 & (33) & 05.13 & 26 & 20.25 & 20 & 68.81 & 15 \\
\hline 11 & 24 & 73.35 & 65 & 23.07 & 44 & 73.16 & (60) & 24.05 & (50) & 75.86 & 10 & 4990.00 & 25 & 36.65 & 30 & 4884.72 & 20 & 4897.49 & 11 & 47.14 & 20 \\
\hline 12 & 23 & 49.65 & (85) & 4999. 99 & (90) & 51.28 & 55 & 02.86 & (60) & 55.74 & 10 & 66.60 & 18 & 14.62 & 25 & 63.34 & 15 & 73.87 & 16 & 24.50 & 14 \\
\hline 13 & 22 & 25.47 & 45 & 76.72 & 55 & 28.11 & 50 & 4881.10 & 17 & 35.32 & 9 & 43.75 & 30 & 4892.12 & 20 & 41.30 & 15 & 49.25 & 27 & & \\
\hline 14 & 21 & 4999.99 & (90) & 51.77 & 45 & 03.87 & 20 & 59. 80 & 15 & - & -. & 18. 74 & 15 & 67.81 & 95 & 19.02 & 15 & 24.50 & 14 & & \\
\hline 15 & 19 & 75.66 & 50 & 27.77 & 56 & 4880.27 & 30 & 37.78 & 12 & - & -. & 4893. 22 & (35) & 42. 70 & 16 & 4797.56 & 10 & 4799.96 & 13 & & \\
\hline 16 & 18 & 50.46 & 45 & 02.86 & (60) & 56.75 & 25 & - & -- & $\ldots$ & -- & 67.00 & 30 & 16. 60 & 12 & 73.85 & 7 & & & & \\
\hline 17 & 16 & 24.68 & 40 & 4878.40 & 40 & 32.89 & 22 & & -- & & -- & 41.30 & 15 & 4789.45 & 12 & & & & & & \\
\hline 18 & 14 & 4898.51 & 50 & 53.12 & 30 & 08.66 & 20 & - & .. & - & -- & 15.42 & 13 & & & & & & & & \\
\hline 19 & 13 & 72.21 & 28 & 27.59 & 27 & 4784.66 & 15 & & & & & & & & & & & & & & \\
\hline 20 & 11 & 45.34 & 40 & 01.75 & 18 & 60.71 & 10 & & & & & & & & & & & & & & \\
\hline 21 & 9 & 18.41 & 24 & 4776.02 & 17 & & & & & & & & & & & & & & & & \\
\hline 22 & 8 & 4791.47 & 15 & 50.05 & 16 & & & & & & & & & & & & & & & & \\
\hline 23 & 7 & 64. 34 & 23 & 23.66 & 10 & & & & & & & & & & & & & & & & \\
\hline 24 & 6 & 35.54 & 10 & & & & & & & & & & & & & & & & & & \\
\hline
\end{tabular}

${ }^{a}$ vif, vibrational intensity factor. $\quad{ }^{b}$ rif, rotational intensity factor. 
greater than the Doppler half-width, $\gamma_{D}=0.023$ $\mathrm{cm}^{-1}$ ). Hence the maximum emissivity, given by $1-e^{-S / \pi \gamma} L$, would be 0.07 , which is of the observed order of magnitude and definitely well below unity. This rough agreement also tends to confirm that the excitation of the $\mathrm{H}_{2} \mathrm{O}$ vibrational states is predominantly thermal. In the $2.7-\mu$ fundamental, where the integrated intensity of the band is an order of magnitude greater, self-absorption effects would begin to be encountered.

\section{References}

[1] E. K. Plyler and C. J. Humphreys, J. Research NBS 40, 449 (1948) RP1890.

[2] G. Herzberg, Infrared and raman spectra of polyatomic molecules, p. 280 (D. Van Nostrand \& Co., Inc., New York, N. Y., 1945).

[3] W. S. Benedict, unpublished data.

[4] NBS Symposium on Energy Transfer in Hoc Gases, NBS Circular 523, especially papers by W. S. Benedict and E. K. Plyler; H. P. Broida; S. S. Penner; G. Dieke and H. M. Crosswhite; and A. G. Gaydon. Also A. G. Gaydon, Spectroscopy and combustion theory (Chapman \& Hall, Ltd., London, 1948).
[5] R. C. Nelson, Atlas and wavelength tables showing the absorption of water vapor in the regions 1.33 to 1.48 and 1.77 to 1.98 microns (Department of Physics, Northwestern University, Evanston, Ill., 1949).

[6] W. S. Benedict and E. K. Plyler, J. Chem. Phys. 21, 498 (1953).

[7] G. A. Hornbeck and R. C. Herman, Ind. Eng. Chem. 43, 2739 (1951).

[8] J. Taylor, W. S. Benedict, and J. Strong, J. Chem. Phys. 20, 1884 (1952).

[9] O. C. Mohler, R. R. McMath, A. K. Pierce, and L. Goldberg, Photometric atlas of the near infrared solar spectrum, (University of Michigan, Ann Arbor, 1951).

[10] P. C. Cross, R. M. Hainer, and G. W. King, J. Chem. Phys. 12, 210 (1949).

[11] D. F. Eggers and B. L. Crawford, Jr., J. Chem. Phys. 19, 1554 (1951).

[12] B. T. Darling and D. M. Dennison, Phys. Rev. 5\%, 128 (1940).

[13] G. H. Dieke, Phys. Rev. 60, 523 (1941).

[14] W. S. Benedict and E. K. Plyler, J. Research NBS 46, 246 (1951) RP2194.

[15] W. S. Benedict, H. H. Claassen, and J. H. Shaw, J. Research NBS 49, 91 (1952) RP2347.

[16] R. D. Cowan and G. H. Dieke, Rev. Mod. Phys. 20, 418 (1948).

[17] S. S. Penner, J. Chem. Phys. 21, 31 (1953).

Washington, August 12, 1953. 